Cochrane Database of Systematic Reviews

\title{
Physical exercise for people with cirrhosis (Review)
}

Aamann L, Dam G, Rinnov AR, Vilstrup H, Gluud LL

Aamann L, Dam G, Rinnov AR, Vilstrup H, Gluud LL.

Physical exercise for people with cirrhosis.

Cochrane Database of Systematic Reviews 2018, Issue 12. Art. No.: CD012678.

DOI: 10.1002/14651858.CD012678.pub2.

www.cochranelibrary.com

Physical exercise for people with cirrhosis (Review) 
TABLE OF CONTENTS

HEADER 1

ABSTRACT

PLAIN LANGUAGE SUMMARY

SUMMARY OF FINDINGS

BACKGROUND

OBJECTIVES

METHODS

RESULTS

Figure 1.

Figure 2.

Figure 3.

DISCUSSION

AUTHORS' CONCLUSIONS

ACKNOWLEDGEMENTS

REFERENCES

CHARACTERISTICS OF STUDIES

DATA AND ANALYSES

Analysis 1.1. Comparison 1 Exercise versus control, Outcome 1 All-cause mortality.

Analysis 1.2. Comparison 1 Exercise versus control, Outcome 2 Serious adverse events.

Analysis 1.3. Comparison 1 Exercise versus control, Outcome 3 Health-related quality of life.

Analysis 1.4. Comparison 1 Exercise versus control, Outcome 4 Non-serious adverse events.

Analysis 1.5. Comparison 1 Exercise versus control, Outcome 5 Anthropometric measurements: lean body mass (kg).

Analysis 1.6. Comparison 1 Exercise versus control, Outcome 6 Anthropometric measurements: mid-arm circumference $(\mathrm{cm})$.

Analysis 1.7. Comparison 1 Exercise versus control, Outcome 7 Anthropometric measurements: thigh circumference $(\mathrm{cm})$. ....

Analysis 1.8. Comparison 1 Exercise versus control, Outcome 8 Anthropometric measurements: body mass index $(\mathrm{kg} / \mathrm{m} 2)$. ....

Analysis 1.9. Comparison 1 Exercise versus control, Outcome 9 Physical fitness: peak oxygen uptake (mL/kg/minute). ...........

Analysis 1.10. Comparison 1 Exercise versus control, Outcome 10 Physical fitness: 6-Minute Walk Test (m in total). ................

Analysis 1.11. Comparison 1 Exercise versus control, Outcome 11 Blood glucose (mmol/L).

Analysis 1.12. Comparison 1 Exercise versus control, Outcome 12 Serum albumin (g/L).

Analysis 1.13. Comparison 1 Exercise versus control, Outcome 13 Serum creatinine $(\mu \mathrm{mol} / \mathrm{L})$.

Analysis 1.14. Comparison 1 Exercise versus control, Outcome 14 Ammonia ( $\mu \mathrm{mol} / \mathrm{L}$ ).

ADDITIONAL TABLES

APPENDICES

CONTRIBUTIONS OF AUTHORS

DECLARATIONS OF INTEREST

SOURCES OF SUPPORT

DIFFERENCES BETWEEN PROTOCOL AND REVIEW

INDEX TERMS 
[Intervention Review]

\section{Physical exercise for people with cirrhosis}

Luise Aamann¹, Gitte Dam¹, Anders R Rinnov², Hendrik Vilstrup ${ }^{1}$, Lise Lotte Gluud³

1Department of Hepatology and Gastroenterology, Aarhus University Hospital, Aarhus, Denmark. ${ }^{2}$ Centre for Physical Activity Research, Rigshospitalet, Copenhagen University Hospital, Copenhagen, Denmark. ${ }^{3}$ Gastrounit, Medical Division, Copenhagen University Hospital Hvidovre, Hvidovre, Denmark

Contact address: Luise Aamann, Department of Hepatology and Gastroenterology, Aarhus University Hospital, Palle Juul-Jensens Boulevard 99, Aarhus, 8200 N, Denmark. luise.aamann@gmail.com, luise.aamann@auh.rm.dk.

Editorial group: Cochrane Hepato-Biliary Group.

Publication status and date: New, published in Issue 12, 2018.

Citation: Aamann L, Dam G, Rinnov AR, Vilstrup H, Gluud LL. Physical exercise for people with cirrhosis. Cochrane Database of Systematic Reviews 2018, Issue 12. Art. No.: CD012678. DOI: 10.1002/14651858.CD012678.pub2.

Copyright @ 2018 The Cochrane Collaboration. Published by John Wiley \& Sons, Ltd.

\section{A B S T R A C T}

\section{Background}

Loss of muscle mass and muscle weakness are common complications to cirrhosis and are associated with increased morbidity and mortality. Therefore, physical exercise may benefit people with cirrhosis.

\section{Objectives}

To assess the beneficial and harmful effects of physical exercise versus sham exercise or no exercise for people with cirrhosis.

\section{Search methods}

We searched The Cochrane Hepato-Biliary Group Controlled Trials Register, the Cochrane Central Register of Controlled Trials (CENTRAL), MEDLINE Ovid, Embase Ovid, and three other databases, including manual searches through reference lists, abstracts, and presentations at conferences and meetings, Google Scholar, and online trial registers in February 2018.

\section{Selection criteria}

We included randomised clinical trials regardless of publication status or language. Inclusion criteria were cirrhosis irrespective of the aetiology or stage. Interventions were physical exercise compared with sham exercise or no intervention.

\section{Data collection and analysis}

Three review authors independently extracted data. We undertook meta-analyses and presented results using risk ratios (RR) for dichotomous outcomes and mean differences (MD) for continuous outcomes, both with $95 \%$ confidence intervals $(\mathrm{Cl})$ and $\mathrm{I}^{2}$ values as markers of imprecision and heterogeneity. We assessed bias control using the Cochrane Hepato-Biliary Group domains and determined the credibility of the evidence using GRADE.

\section{Main results}

We included six randomised clinical trials with 173 participants. All participants had Child-Pugh stage A or B cirrhosis. The intervention groups participated in eight to 14 weeks of physical exercise (aerobic: three trials; resistance: one trial; or aerobic plus resistance training: two trials). Control groups underwent sham exercise (supervised relaxation: one trial) or no intervention (five trials). None of the 89 participants allocated to exercise versus two of 84 participants in the control group died (RR $0.19,95 \% \mathrm{Cl} 0.01$ to 3.73 ; moderate-quality evidence). The cause of death was acute-on-chronic liver disease for both participants. Nine participants in the exercise group and 13 in the control group experienced serious adverse events (RR $0.61,95 \% \mathrm{Cl} 0.19$ to 1.94 ; low-quality evidence). 
Physical exercise showed no beneficial or detrimental effect on health-related quality of life assessed by the Chronic Liver Disease Questionnaire (MD 0.11, 95\% Cl -0.44 to 0.67 ; low-quality evidence). Likewise, physical exercise had no clear effect on physical fitness measured by peak exercise oxygen uptake (MD $0.3 \mathrm{~mL} / \mathrm{kg} /$ minute, $95 \% \mathrm{Cl}-2.74$ to 3.35; low-quality evidence) and Six-Minute Walk Test (MD $56.06 \mathrm{~min}, 95 \% \mathrm{Cl}-9.14$ to 121.26; very low-quality evidence). Physical exercise showed no clear effect on mid-thigh circumference (MD $1.76 \mathrm{~cm}, 95 \% \mathrm{Cl}-0.26$ to 3.77 ; low-quality evidence), but showed an increase in mid-arm circumference (MD $2.61 \mathrm{~cm}, 95 \% \mathrm{Cl} 0.36$ to 4.85; low-quality evidence).

\section{Authors' conclusions}

We found no clear beneficial or harmful effect of physical exercise on mortality, morbidity, or health-related quality of life. Further evidence is needed to evaluate the beneficial and harmful effects of physical exercise on clinical outcomes.

\section{PLAIN LANGUAGE SUMMARY}

\section{Does physical exercise have beneficial or harmful effects in cirrhosis?}

\section{Background}

Prolonged damage of the liver can cause scar tissue formation, which ultimately replaces healthy liver tissue and results in chronic damage (cirrhosis). People with cirrhosis often suffer loss of muscle mass and muscle strength. Therefore, physical exercise may be beneficial to people with cirrhosis.

\section{Review question}

We investigated the beneficial and harmful effects of physical exercise compared with sham exercise (for example, supervised relaxation sessions) or no exercise for people with cirrhosis.

\section{Search date}

February 2018.

\section{Study funding sources}

None of the included trials received industry funding or support from the pharmaceutical or device industry.

\section{Study characteristics}

We included six randomised clinical trials (where people are randomly allocated to one of two groups) with 173 participants. All participants had cirrhosis. Interventions consisted of different types of exercise including bicycling, treadmill walking, and weight lifting. Programmes were home-based or supervised and lasted between eight and 14 weeks.

\section{Key results}

Physical exercise did not seem to affect mortality (death), side effects or quality of life.

\section{Quality of the evidence}

Overall, the evidence for the effect of physical exercise was of low or very low quality. Factors that downgraded the quality of the evidence included lack of trials with a low risk of bias, small trials, and not similar results across trials. 


\begin{tabular}{|c|c|c|c|c|c|c|}
\hline Summary of findings for the main & mparison. Exercise con & pared to no exercis & r people with ci & hosis & & \\
\hline \multicolumn{7}{|c|}{ Exercise compared to no exercise for people with cirrhosis } \\
\hline \multicolumn{7}{|c|}{$\begin{array}{l}\text { Patient or population: people with Child-Pugh stage A or B cirrhosis } \\
\text { Setting: outpatients } \\
\text { Intervention: } 8-14 \text { weeks of physical exercise (aerobic } 3 \text { RCTs; resistance } 1 \text { RCT; or a combination of aerobic and resistance training } 2 \text { RCTs) } \\
\text { Comparison: sham exercise (supervised relaxation } 1 \text { RCT) or no exercise ( } 5 \text { RCTs) }\end{array}$} \\
\hline \multirow[t]{2}{*}{ Outcomes } & \multicolumn{2}{|c|}{ Anticipated absolute effects ${ }^{\star}(95 \% \mathrm{Cl})$} & \multirow{2}{*}{$\begin{array}{l}\text { Relative effect } \\
(95 \% \mathrm{Cl})\end{array}$} & \multirow{2}{*}{$\begin{array}{l}\text { № of partici- } \\
\text { pants } \\
\text { (studies) }\end{array}$} & \multirow{2}{*}{$\begin{array}{l}\text { Qualityof the } \\
\text { evidence } \\
\text { (GRADE) }\end{array}$} & \multirow[t]{2}{*}{ Comments } \\
\hline & Risk with no exercise & Risk with exercise & & & & \\
\hline \multirow{2}{*}{$\begin{array}{l}\text { All-cause mortality } \\
\text { Follow-up: range 8-14 weeks }\end{array}$} & Study population & & \multirow{2}{*}{$\begin{array}{l}\text { RR } 0.19 \\
(0.01 \text { to } 3.73)\end{array}$} & \multirow{2}{*}{$\begin{array}{l}173 \\
(6 \text { RCTs })\end{array}$} & \multirow{2}{*}{$\begin{array}{l}\oplus \oplus \oplus \ominus \\
\text { Moderate }^{a}\end{array}$} & \\
\hline & 24 per 1000 & $\begin{array}{l}5 \text { per } 1000 \\
(0 \text { to } 89)\end{array}$ & & & & \\
\hline \multirow{2}{*}{$\begin{array}{l}\text { Serious adverse events } \\
\text { Follow-up: range } 8-14 \text { weeks }\end{array}$} & Study population & & \multirow{2}{*}{$\begin{array}{l}\mathbf{R R} \mathbf{0 . 6 1} \\
(0.19 \text { to } 1.94)\end{array}$} & \multirow{2}{*}{$\begin{array}{l}173 \\
(6 \mathrm{RCTs})\end{array}$} & \multirow{2}{*}{$\begin{array}{l}\oplus \oplus \ominus \ominus \\
\text { Lowb }\end{array}$} & \multirow[t]{2}{*}{-} \\
\hline & 155 per 1000 & $\begin{array}{l}94 \text { per } 1000 \\
(29 \text { to } 300)\end{array}$ & & & & \\
\hline $\begin{array}{l}\text { Health-related quality of life - CLDQ } \\
\text { (total score } 1-7 \text {, high score corre- } \\
\text { sponds to a better HRQoL) } \\
\text { Follow-up: range } 8-14 \text { weeks }\end{array}$ & $\begin{array}{l}\text { The mean quality of life - } \\
\text { CLDQ (total score) ranged } \\
\text { from } 5.03 \text { to } 5.39\end{array}$ & $\begin{array}{l}\text { MD } 0.11 \text { higher } \\
\text { (0.44 lower to } 0.67 \\
\text { higher) }\end{array}$ & - & $\begin{array}{l}81 \\
\text { (3 RCTs) }\end{array}$ & $\begin{array}{l}\oplus \oplus \odot \ominus \\
\text { Low }^{b}\end{array}$ & - \\
\hline $\begin{array}{l}\text { Anthropometric measurements: } \\
\text { mid-arm circumference }(\mathbf{c m}) \\
\text { Follow-up: range } 12-13 \text { weeks }\end{array}$ & $\begin{array}{l}\text { The mean mid-arm cir- } \\
\text { cumference }(\mathrm{cm}) \text { ranged } \\
\text { from } 27.1 \text { to } 31.5\end{array}$ & $\begin{array}{l}\text { MD } 2.61 \text { higher } \\
\text { (0.36 higher to } 4.85 \\
\text { higher) }\end{array}$ & - & $\begin{array}{l}72 \\
(3 \mathrm{RCTs})\end{array}$ & $\begin{array}{l}\oplus \oplus \odot \ominus \\
\text { Low }^{b}\end{array}$ & - \\
\hline $\begin{array}{l}\text { Anthropometric measurements: } \\
\text { mid-thigh circumference }(\mathbf{c m}) \\
\text { Follow-up: range } 8-13 \text { weeks }\end{array}$ & $\begin{array}{l}\text { The mean mid-thigh cir- } \\
\text { cumference }(\mathrm{cm}) \text { ranged } \\
\text { from } 51.8 \text { to } 54.6\end{array}$ & $\begin{array}{l}\text { MD } 1.76 \text { higher } \\
\text { (0.26 lower to } 3.77 \\
\text { higher) }\end{array}$ & - & $\begin{array}{l}128 \\
\text { (5 RCTs) }\end{array}$ & $\begin{array}{l}\oplus \oplus \ominus \ominus \\
\text { Lowb }\end{array}$ & - \\
\hline $\begin{array}{l}\text { Physical fitness: peak exercise oxy- } \\
\text { gen uptake ( } \mathrm{mL} / \mathbf{k g} / \text { minute) } \\
\text { Follow-up: range } 8-14 \text { weeks }\end{array}$ & $\begin{array}{l}\text { The mean peak exercise } \\
\text { oxygen uptake }(\mathrm{mL} / \mathrm{kg} / \\
\text { minute) ranged from } 21.2 \\
\text { to } 26.1\end{array}$ & $\begin{array}{l}\text { MD } 0.3 \text { higher } \\
\text { (2.74 lower to } 3.35 \\
\text { higher) }\end{array}$ & - & $\begin{array}{l}100 \\
(4 \mathrm{RCTs})\end{array}$ & $\begin{array}{l}\oplus \oplus \odot \odot \\
\text { Low }^{b}\end{array}$ & - \\
\hline
\end{tabular}

Setting: outpatients

Intervention: 8-14 weeks of physical exercise (aerobic 3 RCTs; resistance 1 RCT; or a combination of aerobic and resistance training 2 RCTs) 
Physical fitness: 6-Minute Walk Test

(min in total)

Follow-up: range 8-13 weeks
The mean 6-Minute Walk

Test ( $\mathrm{min}$ in total) ranged

from 309 to 546
MD 56.06 higher

9.14 lower to 121.26

higher)
${ }^{\star}$ The risk in the intervention group (and its $95 \%$ confidence interval) is based on the assumed risk in the comparison group and the relative effect of the intervention (and its $95 \% \mathrm{Cl})$.

Cl: confidence interval; CLDQ: Chronic Liver Disease Questionnaire; HRQoL: health-related quality of life; MD: mean difference; RCT: randomised clinical trial; RR: risk ratio

\section{GRADE Working Group grades of evidence}

High quality: we are very confident that the true effect lies close to that of the estimate of the effect.

Moderate quality: we are moderately confident in the effect estimate: the true effect is likely to be close to the estimate of the effect, but there is a possibility that it is substantially different.

Low quality: our confidence in the effect estimate is limited: the true effect may be substantially different from the estimate of the effect.

Very low quality: we have very little confidence in the effect estimate: the true effect is likely to be substantially different from the estimate of effect.

a Downgraded one level due to serious imprecision (insufficient statistical power).

bDowngraded two levels due to within-trial risk of bias (lack of trials with a low risk of bias, one level) and serious imprecision (insufficient statistical power, one level).

'Downgraded three levels due to within-trial risk of bias (lack of trials with a low risk of bias, one level); inconsistency (between-trial heterogeneity identified although only four trials were included, one level); and very serious imprecision (insufficient statistical power, one level). 


\section{B A C K G R O U N D}

\section{Description of the condition}

Cirrhosis is responsible for $2 \%$ of all deaths globally and is associated with decreased health-related quality of life (Marchesini 2001; Zatoński 2010; Mokdad 2014; Scaglione 2015). Malnutrition and consequently sarcopenia are common complications of cirrhosis; both are associated with increased mortality and morbidity (Saunders 1981; D'Amico 1986; de Jongh 1992; D'Amico 2006; Dasarathy 2012; Montano-Loza 2012; Periyalwar 2012; Hayashi 2013; Meza-Junco 2013; Thiele 2013; Córdoba 2014; Montano-Loza 2014). Important contributing factors include poor dietary intake, hypermetabolism, increased protein loss to the intestines, and decreased protein synthesis in the liver which leads to loss of skeletal muscle mass and muscle strength. Even after liver transplantation, pretransplant exercise capacity predicts posttransplant survival (Jones 2012; Lemyze 2013). Decreased exercise capacity predicts mortality, irrespective of the aetiology of the underlying liver disease (Biagini 2006; Hollingsworth 2008; Cerri 2010; Hollingsworth 2010; Galant 2012). Reduced exercise capacity is associated with the severity of the underlying liver disease, but even people with compensated cirrhosis are affected compared to healthy people (Hayashi 2012; Galant 2013).

Physical fitness predicts morbidity and mortality in several populations (Puhan 2013; Bernal 2014; Hellberg 2014). Muscle wasting is difficult to diagnose in the clinical setting, where symptoms such as weakness and fatigue are diffuse and likely to be present in people with chronic disease. The available methods have limitations primarily due to a lack of objectivity, reproducibility, and prognosis discrimination (Periyalwar 2012; Montano-Loza 2014). Trials that include people without cirrhosis include body mass index (BMI) to indicate muscle mass and malnutrition (Woo 2015). However, in people with cirrhosis, ascites and peripheral oedema can affect the assessment of BMI. Other physical measurements, which include assessment of the grip-strength, appendicular lean mass, knee flexion, and knee extension, are objective but have low reproducibility (McLean 2014). Clinical studies have used computed tomography scan, magnetic resonance imaging and dual energy $\mathrm{x}$-ray absorptiometry to quantify muscle mass (Dasarathy 2012; Montano-Loza 2013; Román 2014), and the peak and maximum oxygen consumption to quantify exercise capacity/physical fitness (Bandi 1998; Degoricija 2003; Faustini-Pereira 2015).

\section{Description of the intervention}

The management of people with cirrhosis is aimed at controlling and alleviating cirrhosis-related complications. Liver transplantation may be curative, but this option is both costly and often unavailable due to donor shortage. Insertion of a transjugular intrahepatic portosystemic shunt, which reduces portal pressure, may reverse sarcopenia (Tsien 2013). However, the complications include hepatic encephalopathy and heart failure. Previous studies show that sarcopenia is the primary nutritional consequence of malnutrition but factors such as metabolic changes, chronic inflammation, and haemodynamic changes are also important (Periyalwar 2012; Montano-Loza 2013). Improved nutrition may not in itself be enough to reverse sarcopenia. Physical exercise enhances or maintains physical muscle strength (Nelson 2007), but it also beneficially affects muscle mass, weight, and the cardiovascular system (Román 2014; Zenith 2014). The main types of physical exercise include aerobic exercise, resistance training (anaerobic exercise), flexibility, and balance. Aerobic exercise increases the uptake of oxygen in the larger muscle groups and has a beneficial effect on cardiovascular homeostasis. Resistance training mainly affects muscle strength and mass whereas flexibility and balance exercise improve the range of motion necessary for daily activity and diminish the risk of falls (NIH 2006; Nelson 2007).

\section{How the intervention might work}

The expected effects of physical exercise in people with cirrhosis are complex. Exercise improves glucose metabolism in both men and women, and aerobic as well as anaerobic exercise improve insulin sensitivity (Mikines 1989). This effect is important considering the known association between cirrhosis and insulin resistance (Campillo 1990a; Goswami 2014). Cirrhosis is also associated with a disrupted balance in protein synthesis and degradation (Morrison 1990). Repeated performance of resistance training for longer periods causes hypertrophy of skeletal muscle, as it increases muscle protein turnover. Following resistance training, protein synthesis is elevated for up to 48 hours and the synthesis of protein is regulated primarily at the level of translation and involves changes in signal transduction (Bolster 2004). The mammalian target of rapamycin (mTOR) is the important regulator of muscle protein synthesis.

In liver failure, ammonia removal in the liver is reduced and muscle can act as an alternative route of ammonia detoxification (Dam 2011). Physical exercise causes skeletal muscle hypertrophy, and hence may enhance the removal of ammonia. This decreases the risk of developing hepatic encephalopathy (Córdoba 2008). Increased ammonia concentration leads to autophagy (Polletta 2015), which also contributes to sarcopenia. Physical exercise may lower ammonia concentrations and ameliorate the sarcopenia. Finally, cirrhosis is a proinflammatory state that contributes to the development of sarcopenia and decreased protein synthesis. Studies showed that exercise limits systemic inflammation (Lavie 2011); thus, it might decrease protein degradation and support muscle protein synthesis.

\section{Why it is important to do this review}

There is a large body of evidence that shows the negative clinical consequences of the reduced exercise capacity in cirrhosis. People with cirrhosis are less physically active than healthy people and supervised exercise is generally recommended (Hayashi 2012). However, the optimum exercise programme is not known (Toshikuni 2014). Several randomised clinical trials (RCTs) have evaluated the effect of exercise versus no intervention for people with cirrhosis (Román 2014; Zenith 2014; Román 2016). One RCT including 19 participants with cirrhosis evaluated eight weeks of aerobic exercise versus no intervention (Zenith 2014). The trial found that exercise increased peak oxygen consumption and muscle mass and reduced fatigue. Another RCT with 17 participants evaluated exercise capacity, muscle mass, and health-related quality of life after a 12-week supervised exercise programme versus no intervention (Román 2014). The trial found a beneficial effect of exercise on all three outcomes. The increased muscle mass may theoretically also reduce blood ammonia levels, and, therefore, be associated with a beneficial effect on hepatic encephalopathy (Córdoba 2008). One RCT found a beneficial effect of exercise versus no intervention on ammonia (Román 2014), but others found that blood ammonia increased (Sinniah 
1970). The difference may reflect the severity of the underlying liver disease, as well as the intensity level of the exercise. At present, there are no studies that show a beneficial effect on manifestations of hepatic encephalopathy. However, current evidence remains inconclusive, and a potential damaging effect remains possible in certain groups. Furthermore, physical exercise may have a detrimental effect on portal pressure and blood flow to the muscles and brain in people with cirrhosis (Bandi 1998; García-Pagàn 1998; Premaratna 2002; Bay Nielsen 2005). One study that included 39 participants found that cirrhosis was associated with reduced oxygen consumption, myocardial thickening, and ventricular stiffness leading to decreased diastolic function as well as inotropic and chronotropic incompetence under conditions of stress (Wong 2001). Accordingly, cirrhotic cardiomyopathy may worsen the reduced exercise capacity but also negatively affect the beneficial effect of aerobic exercise. Likewise, one RCT that included 25 participants with cirrhosis found that moderate physical exercise combined with propranolol versus placebo increased the hepatic venous pressure gradient (HVPG) and decreased hepatic blood flow (Bandi 1998). Exercise also has a potential detrimental effect on pulmonary gas exchange (Lemyze 2011; Lemyze 2013) and on electrocardiogram changes such as ST segment depression in the absence of coronary artery stenosis (Mori 2007). Theoretically, redistribution of blood from splanchnic organs to the central circulation could limit blood supply to skeletal muscles and the brain during exercise. However, one study that evaluated incremental cycling to exhaustion found that blood redistribution from splanchnic organs did not limit blood flow to the muscles or the brain (Bay Nielsen 2005). Therefore, the body of evidence is complex. We have not identified any systematic reviews that evaluate the effects of physical exercise on people with cirrhosis.

\section{O B JECTIVES}

To assess the beneficial and harmful effects of physical exercise versus sham exercise or no exercise for people with cirrhosis.

\section{METHODS}

\section{Criteria for considering studies for this review}

\section{Types of studies}

We included RCTs regardless of publication status or language. During the selection of trials, we watched out for observational studies (i.e. quasi-randomised studies, cohort studies, or patient reports) that reported adverse events caused by or associated with the interventions in our review. However, we did not specifically search for such observational studies for inclusion in this review, which is a known limitation of our systematic review.

\section{Types of participants}

We included participants with cirrhosis of any age or sex, irrespective of the severity or aetiology.

\section{Types of interventions}

Any form of exercise, irrespective of the type, intensity, or duration of the intervention versus sham exercise or no exercise.

We allowed cointerventions such as diets, non-absorbable disaccharides, or antibiotics if administered equally to the intervention and control group.

\section{Types of outcome measures}

We evaluated all outcomes at the maximum follow-up.

\section{Primary outcomes}

- All-cause mortality.

- Serious adverse events. We defined serious adverse events as any untoward medical occurrence that resulted in death, was life-threatening, required hospitalisation or prolongation of existing hospitalisation, or resulted in persistent or significant disability or incapacity or required intervention to prevent it (ICH-GCP 1997).

- Health-related quality of life.

\section{Secondary outcomes}

- Non-serious adverse events.

- Anthropometric measurements: lean body mass (measured using dual energy $x$-ray absorptiometry scans, magnetic resonance imaging, computerised tomography, or ultrasound), mid-arm circumference, thigh circumference, and BMI.

- Physical fitness: maximum/peak oxygen uptake, Six-Minute Walk Test, two-minute step test, hand grip strength, onerepetition maximum kicking strength.

\section{Exploratory outcomes}

- Insulin resistance (homeostasis model assessment of insulin resistance, glucose infusion rate during insulin clamp).

- Glycaemic control (glycated haemoglobin A1c, fasting blood glucose, response to oral glucose tolerance test).

- Serum albumin concentration.

- Serum creatinine concentration.

- Nitrogen balance.

- Portal venous pressure.

\section{Search methods for identification of studies}

\section{Electronic searches}

We performed electronic searches of The Cochrane HepatoBiliary Group Controlled Trials Register (Cochrane Hepato-Biliary Group Module), the Cochrane Central Register of Controlled Trials (CENTRAL) in the Cochrane Library, MEDLINE Ovid, Embase Ovid, LILACS (Bireme), Science Citation Index Expanded (Web of Science), and Conference Proceedings Citation Index - Science (Web of Science) (Royle 2003). Appendix 1 provides the search strategies with the time spans of the searches.

With assistance from the Information Specialist of The Cochrane Hepato-Biliary Group, we planned to search Russian, Chinese, and Japanese databases for publications of interest. However, these searches were unavailable.

\section{Searching other resources}

We scanned the reference lists of relevant articles and proceedings from meetings of the British Society for Gastroenterology (BSG), the British Association for the Study of the Liver (BASL), the European Association for the Study of the Liver (EASL), the United European Gastroenterology Week (UEGW), the American Gastroenterological Association (AGA), the American Association for the Study of Liver Diseases (AASLD), and the International Society for Hepatic Encephalopathy and Nitrogen Metabolism (ISHEN) and wrote to 
the principal investigators of trials for additional information about completed trials and for information about any ongoing trials.

We searched Google Scholar using the key words: cirrhosis, exercise, and trial.

Finally, we searched online trial registries such as ClinicalTrial.gov (www.clinicaltrials.com), the European Medicines Agency (EMA) (www.ema.europa.eu/ema/), the World Health Organization International Clinical Trial Registry Platform (www.who.int/ictrp), the Food and Drug Administration (FDA) (www.fda.gov), and pharmaceutical company sources for ongoing or unpublished trials.

\section{Data collection and analysis}

We followed the guidelines provided in the Cochrane Handbook for Systematic Reviews of Interventions (Higgins 2011) and the Cochrane Hepato-Biliary Group Module.

Two review authors (GD and LA) extracted data from the published trial reports in an independent manner. A third review author (LG) acted as ombudsman in case of disagreements. We wrote to authors of included trials for additional information.

For trials that were described in more than one reference, we used the reference with the most complete information (the largest number of participants and the longest duration of follow-up) but grouped all references for each trial.

\section{Selection of studies}

Two review authors (GD and LA) selected trials identified through the electronic and manual searches using the criteria described above. We listed studies excluded after full-text assessment, along with the reasons for exclusion, in the Characteristics of excluded studies table. We illustrated the trial selection process in a PRISMA diagram. Any disagreements were discussed among the authors until settlement. All review authors participated in the final selection of trials for inclusion.

\section{Data extraction and management}

We extracted the following data.

- Participants: inclusion criteria, mean age, proportion of men, and type of underlying liver disease.

- Interventions: type, intensity, frequency, and duration of interventions and cointerventions.

- Trial: design (parallel or cross-over) setting (hospital or outpatient), number of clinical sites, country of origin, and inclusion period.

We also gathered information about bias control and all outcomes.

\section{Assessment of risk of bias in included studies}

We assessed bias control using the domains described in the Cochrane Hepato-Biliary Group Module and classified risk of bias for separate domains as high, unclear, or low. We also included an overall assessment of bias control as described below.

\section{Allocation sequence generation}

- Low risk of bias: sequence generation achieved using computer random number generation or a random number table. Drawing lots, tossing a coin, shuffling cards, or throwing dice were adequate if performed by an independent person not otherwise involved in the trial.

- Unclear risk of bias: sequence generation method not described.

- High risk of bias: sequence generation method was not random.

\section{Allocation concealment}

- Low risk of bias: used a central and independent randomisation unit or similar adequate method (e.g. serially numbered opaque sealed envelopes) to ensure that the allocation sequence was unknown to the investigators.

- Unclear risk of bias: allocation not described.

- High risk of bias: allocation sequence was likely to be known to the investigators who assigned the participants.

\section{Blinding of participants and personnel}

- Low risk of bias: blinding of participants and personnel using sham exercise. We defined lack of blinding as not likely to affect the evaluation of mortality (Hróbjartsson 2001; Savović 2012).

- Unclear risk of bias: insufficient information to assess blinding.

- High risk of bias: no blinding or incomplete blinding.

\section{Blinding of outcome assessors}

- Low risk of bias: blinding of outcome assessors using sham exercise. We defined lack of blinding as not likely to affect the evaluation of mortality (Hróbjartsson 2001; Savović 2012).

- Unclear risk of bias: insufficient information to assess blinding.

- High risk of bias: no blinding or incomplete blinding.

\section{Incomplete outcome data}

- Low risk of bias: missing data were unlikely to make treatment effects depart from plausible values. The investigators used sufficient methods, such as intention-to-treat analyses with multiple imputations or carry-forward analyses to handle missing data.

- Unclear risk of bias: there was insufficient information to assess missing data.

- High risk of bias: the results were likely to be biased due to missing data.

\section{For-profit bias}

- Low risk of bias: the trial appeared free of industry sponsorship or other type of for-profit support.

- Unclear risk of bias: no information on clinical trial support or sponsorship.

- High risk of bias: the trial was sponsored by industry or received other support (such as provision of study drugs).

\section{Other bias}

- Low risk of bias: the trial appeared free of other biases including: medicinal dosing problems or follow-up (as defined below).

- Unclear risk of bias: the trial may or may not have been free of other domains that could put it at risk of bias.

- High risk of bias: there were other factors in the trial that could put it at risk of bias such as the administration of inappropriate treatments being given to the controls (e.g. an inappropriate 
dose) or follow-up (e.g. the trial included different follow-up schedules for participants in the allocation groups).

\section{Overall bias assessment}

- Low risk of bias: all domains were low risk of bias using the definitions described above.

- High risk of bias: one or more of the bias domains were of unclear or high risk of bias.

\section{Measures of treatment effect}

We used the risk ratio (RR) for dichotomous outcomes and mean differences (MD) for continuous outcomes, both with 95\% confidence intervals $(\mathrm{Cl})$.

\section{Unit of analysis issues}

As expected, we did not identify any cross-over trials. If cross-over trials are identified in future updates, we plan to use data from the first treatment period.

\section{Dealing with missing data}

We extracted data from all participants according to allocation. We planned to evaluate the influence of missing outcome data in dichotomous data (Higgins 2008) based on:

- worst-case scenario analysis: all participants with missing data counted as failures;

- extreme worst-case/best-case scenario analysis: participants with missing outcome data in the exercise arm counted as failures and in the control arm as successes and vice versa (Cochrane Hepato-Biliary Group Module).

However, we did not detect any missing data in our analyses of dichotomous data. Accordingly, we did not undertake worstcase, best-case, or extreme worst-case analyses. None of the trials reported data that allowed us to evaluate the potential influence of missing data in the analyses of continuous outcomes.

\section{Assessment of heterogeneity}

We expressed heterogeneity as 12 statistic values using the thresholds: $0 \%$ to $40 \%$ (unimportant), $40 \%$ to $60 \%$ (moderate), $60 \%$ to $80 \%$ (substantial), and greater than $80 \%$ (considerable).

\section{Assessment of reporting biases}

If this meta-analysis had involved more than 10 included RCTs, we would have assessed reporting and other dissemination biases on visual inspection of funnel plots and regression analyses (Egger 1997; Harbord 2006). Due to the small number of trials, we did not undertake these analyses.

\section{Data synthesis}

We performed our analyses in Review Manager 5 (Review Manager 2014) and Stata (Stata 14).

\section{Meta-analysis}

We conducted random-effects and fixed-effect meta-analyses. In all analyses, the estimates of the models were similar. Therefore, we assumed that any small-study effects had little effect on the intervention effect estimate. For random-effect models, precision decreased with increasing heterogeneity and $\mathrm{Cls}$ widened correspondingly. We reported the results of our analyses based on the random-effects meta-analyses to obtain the most conservative result.

\section{Trial Sequential Analysis}

We planned to perform Trial Sequential Analysis for the primary outcomes with alpha set to $2.5 \%$, beta to $10 \%$ (power to $90 \%$ ), and model-based heterogeneity (Thorlund 2011; TSA 2011; Wetterslev 2017). We defined the required information size as the number of participants needed to detect or reject an intervention effect estimated based on the assumed control risk, the relative risk reduction (RRR), and the model-based diversity. We planned to construct the trial sequential monitoring boundaries based on the required information size (also known as the heterogeneityadjusted required information size) and define firm evidence as being established if the Z-curve (the result of the cumulative metaanalysis) crossed the monitoring boundary for benefit or harm before reaching the required information size. We planned to undertake the analyses with the RRR set to the upper limit of the $95 \% \mathrm{Cl}$ and the observed control group event rate. However, based on the limited number of events and participants, we did not undertake the analyses.

\section{Subgroup analysis and investigation of heterogeneity}

We planned to undertake the following subgroup analyses.

- Sex (men compared to women).

- Severity of liver disease (compensated compared to decompensated and Child-Pugh's Class A or B/C).

- Type of exercise (aerobic compared to non-aerobic).

- Type of control group (no intervention compared to diets).

- Cointerventions.

- Bias control (RCTs assessed as low compared to high risk of bias).

- Publication status (trials published as full paper articles compared to abstracts/unpublished trials).

Based on the small number of trials, we did not undertake any of the planned subgroup analyses.

\section{Sensitivity analysis}

To evaluate the robustness of the overall results, we planned to undertake sensitivity analyses to evaluate the influence of missing outcomes as described above.

\section{'Summary of findings' tables}

We created a 'Summary of findings' table including primary and secondary review outcomes using GRADEpro software (GRADEpro). The GRADE approach appraises the quality of a body of evidence based on the extent to which one can be confident that an estimate of effect or association reflects the item being assessed. The quality of a body of evidence considered within-study risk of bias, indirectness of the evidence (population, intervention, control, outcomes), unexplained heterogeneity or inconsistency of results (including problems with subgroup analyses), imprecision of effect estimates, and risk of publication bias (GRADEpro; Guyatt 2008).

We reported the conclusions using the EPICOT (evidence, population, intervention, comparison, outcome, time stamp; see Implications for research for details) format (Brown 2006). 


\section{RESULTS}

\section{Description of studies}

We included six RCTs (Macías-Rodríguez 2016; Román 2014; Zenith 2014; Román 2016; Aamann 2018; Krüger 2018), and excluded eight studies (Ritland 1983; Campillo 1990b; Degoricija 2003; Konishi 2011; Pattullo 2013; Debette-Gratien 2014; Berzigotti 2016a; Nishida 2016). For additional information, see Characteristics of included studies and Characteristics of excluded studies tables.

\section{Results of the search}

Searching the electronic databases revealed 963 potentially relevant records (Figure 1). The manual searches identified an additional 15 records. We removed duplicates, and screened the titles and abstracts and excluded 652 references. Ultimately, 23 references were retrieved for further assessment. We excluded nine references concerning one RCT and eight observational studies (Ritland 1983; Campillo 1990b; Degoricija 2003; Konishi 2011; Pattullo 2013; Debette-Gratien 2014; Berzigotti 2016a; Nishida 2016; Hiraoka 2017). The remaining 14 references referred to six RCTs which fulfilled the inclusion criteria (Macías-Rodríguez 2016; Román 2014; Zenith 2014; Román 2016; Aamann 2018; Krüger 2018). All six trials used a parallel-arm design and were available as full-text articles. 
Figure 1. Study flow diagram

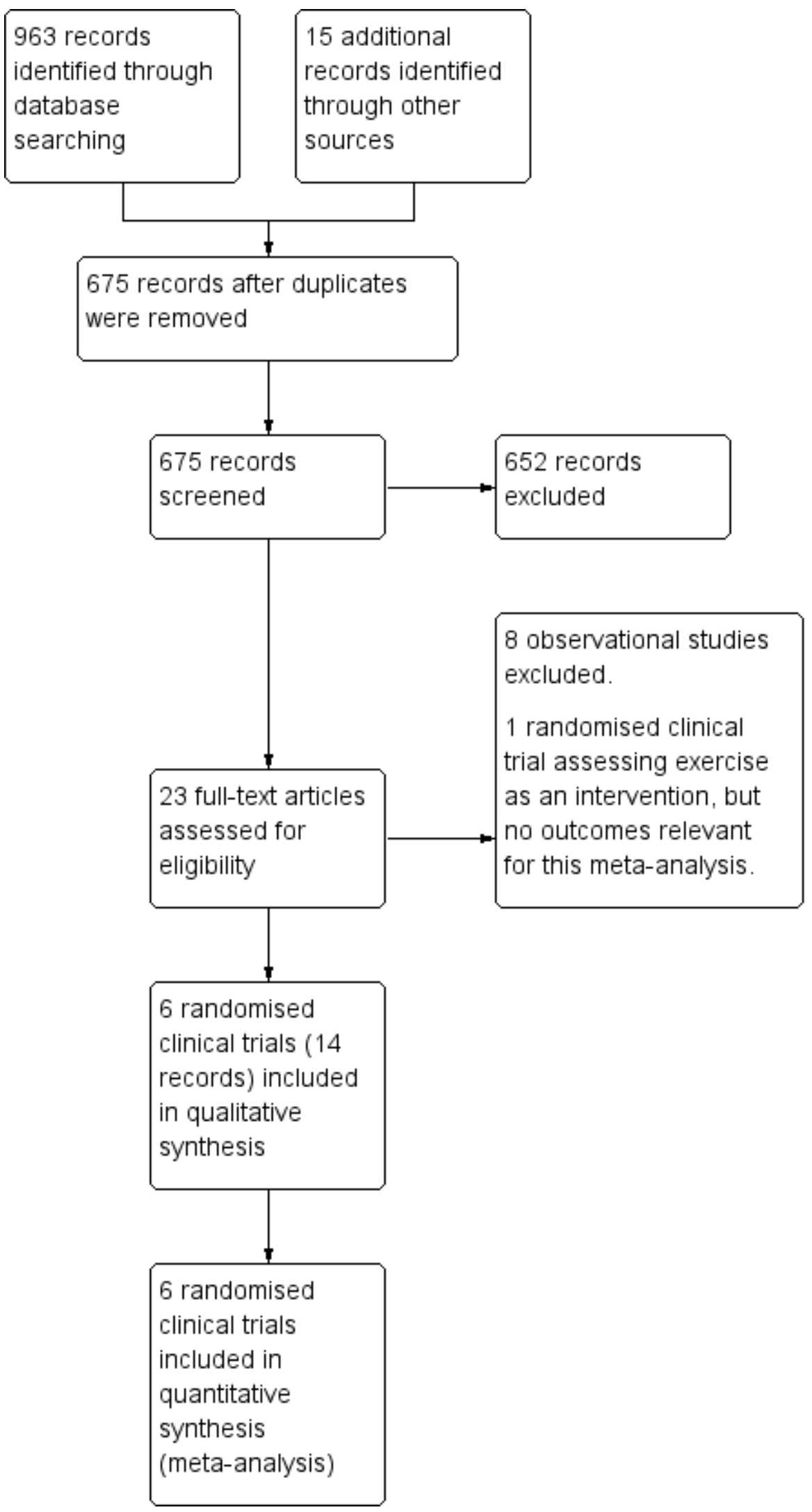




\section{Included studies}

\section{Participants}

We included 173 outpatients with cirrhosis (Child-Pugh A or B). The proportion of men ranged from $50.0 \%$ to $78.9 \%$ in the intervention group and $64.0 \%$ to $83.3 \%$ in the control group. The proportion of participants with alcoholic liver disease varied from $7.7 \%$ to $86 \%$ in the intervention group and $16.7 \%$ to $86.7 \%$ in the control group (see Characteristics of included studies table).

\section{Interventions}

The intervention physical exercise varied in type, intensity, and duration. The different types of exercise performed were aerobic exercise; anaerobic exercise; kinesiotherapy; and flexibility including ergometer cycling, rhythmic activities, treadmill walking, balance, co-ordination, resistance training, and stretching; either solely or as combinations. The sessions were either homebased or supervised at an institution by specialists (e.g. nurses, physiotherapists, cardiologists, sport scientists). The intensity was moderate to high and the duration was 30 minutes to 70 minutes per session three times per week.

Three trials included nutritional therapy in the intervention and control groups (Román 2014; Macías-Rodríguez 2016; Aamann 2018).

\section{Comparators}

One trial included a sham exercise group consisting of supervised relaxation sessions of one hour three times per week (Román 2016). The remaining trials allocated control groups to no intervention (Macías-Rodríguez 2016; Román 2014; Zenith 2014; Aamann 2018; Krüger 2018).

\section{Outcomes}

We gathered outcome data from all trials. The duration of the interventions ranged from eight to 14 weeks in total. Investigators assessed outcomes when terminating each trial intervention. The primary outcomes in the trials included peak voluntary muscle strength, peak exercise oxygen uptake, quality of life, change in muscle mass, and HVPG.

\section{Excluded studies}

We excluded one RCT (Degoricija 2003), and eight observational studies (Ritland 1983; Campillo 1990b; Konishi 2011; Pattullo 2013; Debette-Gratien 2014; Berzigotti 2016a; Nishida 2016; Hiraoka 2017; see Characteristics of excluded studies table).

The RCT evaluated the humoral response of paracentesis, diuretics, and plasma expanders with or without bedrest in participants with cirrhosis and ascites (Degoricija 2003).

The largest observational study included 60 participants with cirrhosis, portal hypertension, and a BMI greater than $26 \mathrm{~kg} / \mathrm{m}^{2}$
(Berzigotti 2016a). All participants underwent a 16-week lifestyle intervention programme consisting of moderate exercise and diet. The lifestyle intervention decreased bodyweight and the HVPG. Adverse events included arthritis (one participant) and worsening of known asthma requiring an increase in bronchodilators dosage (one participant).

The second observational study evaluated a 12-week individualised programme of adapted physical activity in 13 participants awaiting liver transplantation (Debette-Gratien 2014). One participant experienced worsening of the underlying liver disease. There were no other adverse events.

The third observational study included nine participants with compensated cirrhosis (Nishida 2016). All participants did bench step exercises at home and supplemented with oral branched chain amino acids for one year. One participant dropped out due to lower back pain and one developed hepatocellular carcinoma (Nishida 2016).

The fourth observational study tested a home-based exercise programme of optional choice; skiing, running, jogging, swimming, or bicycling for 30 minutes three times per week. The study included nine participants with chronic active hepatitis, a subgroup of five were diagnosed with cirrhosis. Peak oxygen uptake was evaluated at four to six weeks and 10 to 12 weeks. No one experienced worsening in clinical condition (Ritland 1983).

The fifth study examined the aerobic capacity in a subgroup of four of 24 participants with cirrhosis allocating participants to a four- to five-week exercise programme of either 45 minutes or 60 minutes on a bicycle or treadmill (Campillo 1990b).

The sixth observational study only included three participants with cirrhosis out of 17 obese participants with chronic hepatis C. They were followed for eight months with nutritional advice, six months including walking as the intervention (8000 steps per day measured by a pedometer). Two participants dropped out because of knee pain and depression (Konishi 2011).

Using a pedometer, the seventh observational study registered steps walked per day in 33 participants with cirrhosis. Branched chain amino acid (BCAA) supplementations were given as a late night snack and additional 2000 steps per day were prescribed (Hiraoka 2017).

The last observational study to be excluded also involved obese participants with chronic hepatitis C. Only six of 16 participants had cirrhosis. The intervention was a 24-week lifestyle change with nutritional guidance and daily walking (more than 10,000 steps per day). All 16 completed the intervention (Pattullo 2013).

\section{Risk of bias in included studies}

The assessment of bias included information retrieved from the published articles (Figure 2; Figure 3). 
Figure 2. Risk of bias graph: review authors' judgements about each risk of bias item presented as percentages across all included trials

Random sequence generation (selection bias)

Allocation concealment (selection bias)

Blinding of participants and personnel (performance bias)

Blinding of outcome assessment (detection bias)

Incomplete outcome data (attrition bias)

Selective reporting (reporting bias)

For-profit funding

Other bias

Overall risk of bias assessment (non-mortality outcomes)

Overall risk of bias assessment (mortality)

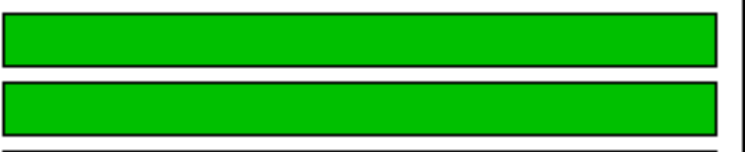

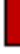
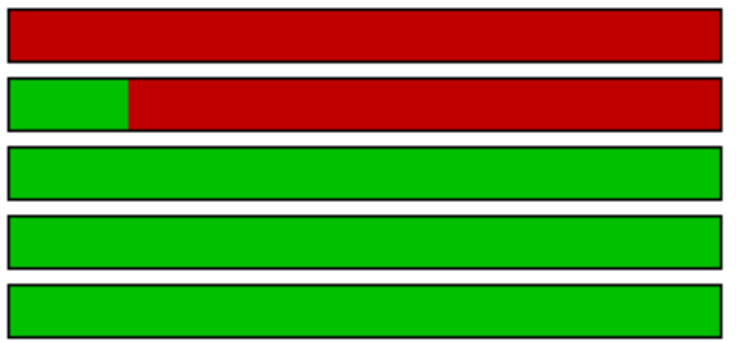

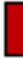
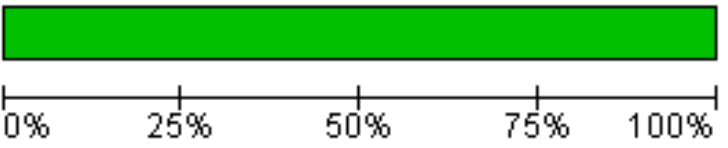

$0 \%$

High risk of bias 
Figure 3. Risk of bias summary: review authors' judgements about each risk of bias item for each included study

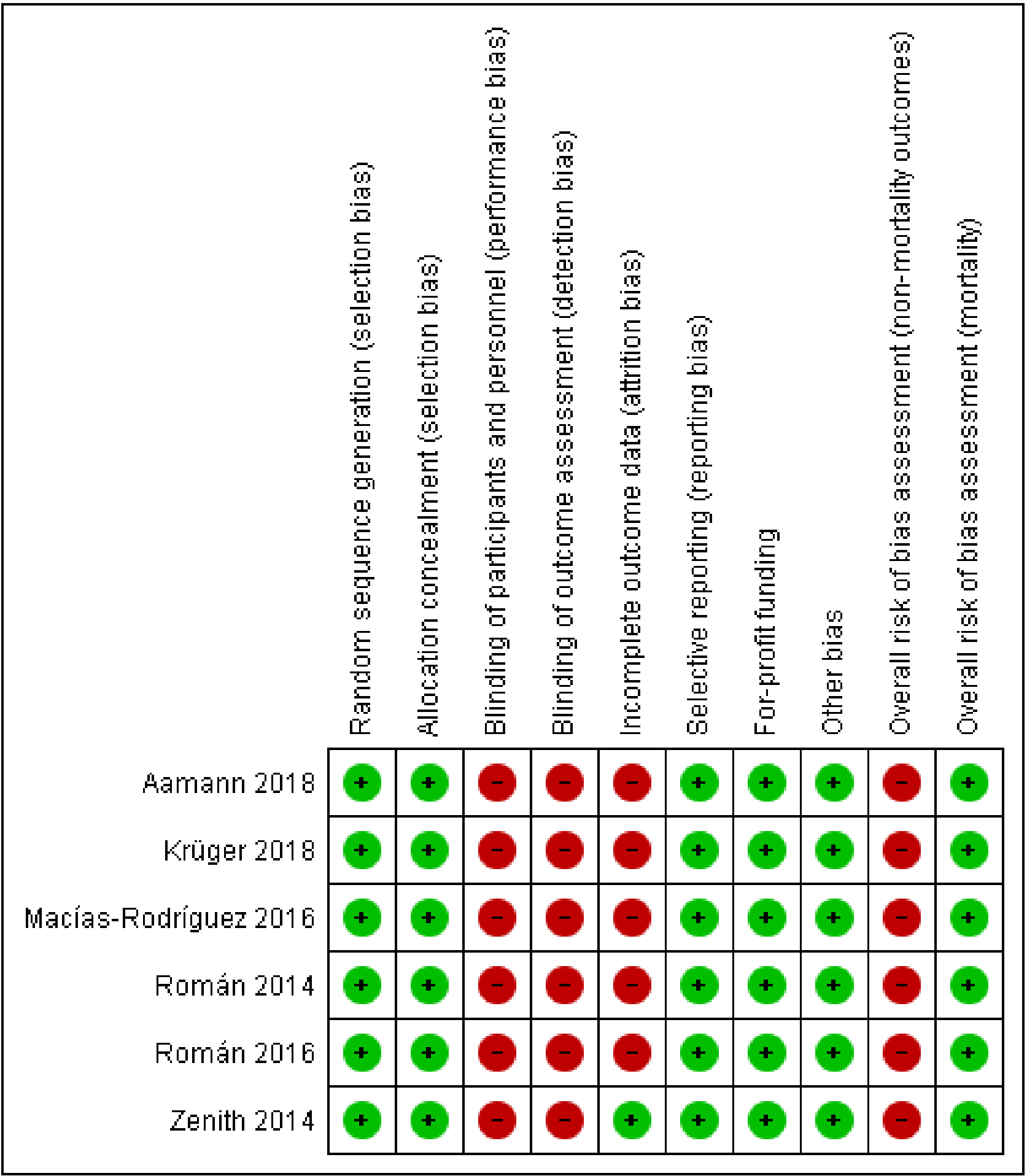

\section{Allocation}

All six trials allocated participants using computer-generated random numbers and serially numbered opaque sealed envelopes (Macías-Rodríguez 2016; Román 2014; Zenith 2014; Román 2016; Aamann 2018; Krüger 2018).
Blinding

As expected, all of the included trials were open without blinding of participants. Blinding of investigators varied (Macías-Rodríguez 2016; Román 2014; Zenith 2014; Román 2016; Aamann 2018; Krüger 2018). 


\section{Incomplete outcome data}

All trials lost participants to follow-up and clarified the reasons for losses in detail. No trials reported intention-to-treat analyses and, therefore, we classified them as high risk of attrition bias.

\section{Selective reporting}

All trials assessed and reported clinically relevant outcomes (Macías-Rodríguez 2016; Román 2014; Zenith 2014; Román 2016; Aamann 2018; Krüger 2018).

\section{For-profit bias}

None of the included trials received industry sponsorships or other types of for-profit support (Macías-Rodríguez 2016; Román 2014; Zenith 2014; Román 2016; Aamann 2018; Krüger 2018).

\section{Other potential sources of bias}

We did not identify other sources of bias in the included trials (Macías-Rodríguez 2016; Román 2014; Zenith 2014; Román 2016; Aamann 2018; Krüger 2018).

\section{Overall bias assessment}

All trials were low risk of bias in the assessment of mortality and high risk of bias in assessment of the remaining outcomes (MacíasRodríguez 2016; Román 2014; Zenith 2014; Román 2016; Aamann 2018; Krüger 2018).

\section{Effects of interventions}

See: Summary of findings for the main comparison Exercise compared to no exercise for people with cirrhosis

See: Summary of findings for the main comparison for the main results from primary outcomes and a selection of secondary outcomes.

\section{Primary outcomes}

\section{All-cause mortality}

In total, 0/89 participants allocated to the exercise group versus 2/84 participants allocated to the control group died (RR 0.19, 95\% $\mathrm{Cl} 0.01$ to 3.73 ; 173 participants, 6 trials; $\mathrm{I}^{2}=0 \%$; Analysis 1.1). The cause of death was acute-on-chronic-liver-disease for both participants.

\section{Serious adverse events}

Eight participants in the exercise group versus 13 in the control group reported serious adverse events (RR $0.61,95 \% \mathrm{Cl} 0.19$ to 1.94 ; 173 participants, 6 trials; $12=31 \%$; Analysis 1.2; Table 1 ). The serious adverse events included variceal bleeding, infections, and cancer (Table 1).

\section{Health-related quality of life}

Five trials assessed health-related quality of life using the Chronic Liver Disease Questionnaire (CLDQ; Zenith 2014; Macías-Rodríguez 2016; Krüger 2018), EuroQol-Visual Analogue Scale (EQ-VAS) (Zenith 2014; Krüger 2018), or the 36-item Short Form (SF-36) questionnaire (Román 2014; Aamann 2018).

Physical exercise had no beneficial or detrimental effects on healthrelated quality of life assessed by the CLDQ (MD $0.11,95 \% \mathrm{Cl}-0.44$ to $0.67 ; 81$ participants, 3 trials; $\left.\right|^{2}=33 \%$ ), the EQ-VAS total score (MD $3.11,95 \% \mathrm{Cl}-24.03$ to $30.24 ; 56$ participants, 2 trials; $12=88 \%$ ), or the SF-36 questionnaire (MD 2.26, $95 \% \mathrm{Cl}-3.84$ to $8.37 ; 51$ participants, 2 trials; $1^{2}=0 \%$ ) (Analysis 1.3).

\section{Secondary outcomes}

\section{Non-serious adverse events}

Physical exercise did not affect the risk of non-serious adverse events (RR 1.97, 95\% Cl 0.53 to $7.33 ; 173$ participants, 6 trials; $\left.\right|^{2}=$ $0 \%$; Analysis 1.4). Events in the exercise group included mild upper respiratory tract infection and transient bradycardia (Román 2014), exacerbation of asthma (Román 2016), iron-deficiency anaemia, knee injury (accident unrelated to the intervention), and worsening of morbus Scheuermann (Aamann 2018). In the control group, the non-serious adverse events included stomatitis and minimal hepatic encephalopathy responsive to treatment with lactulose (Aamann 2018).

\section{Anthropometric measurements}

We found no difference between the intervention and control groups regarding lean body mass assessed using dual-energy x-ray absorptiometry (MD $0.46,95 \% \mathrm{Cl}-2.92$ to $3.84 ; 22$ participants, 1 trial); compression index by ultrasound of the quadriceps muscle (MD $0.07,95 \% \mathrm{Cl}-0.03$ to 0.17 ; 56 participants, 2 trials; $\mathrm{I}^{2}=0 \%$ ); or bioimpedance (MD 2.30, $95 \% \mathrm{Cl}-0.73$ to $5.33 ; 34$ participants, 1 trial) (Analysis 1.5).

Physical exercise increased the mid-arm circumference (MD 2.61, $95 \% \mathrm{Cl} 0.36$ to $4.85 ; 72$ participants, 3 trials; $1^{2}=0 \%$; Analysis 1.6 ), but there was no equivalent difference in mid-thigh circumference (MD $1.76,95 \% \mathrm{Cl}-0.26$ to $3.77 ; 128$ participants, 5 trials; $1^{2}=$ $0 \%$; Analysis 1.7) or in BMI (MD 0.97, $95 \% \mathrm{Cl}-0.48$ to 2.42 ; 154 participants, 6 trials; $\left.\right|^{2}=0 \%$ ) (Analysis 1.8).

\section{Physical fitness}

We gathered data on physical fitness/exercise capacity assessed by measuring peak oxygen uptake (Analysis 1.9) and the SixMinute Walk Test (Analysis 1.10). The analyses showed no effects of physical exercise versus control in peak oxygen uptake (MD $0.30 \mathrm{~mL} /$ $\mathrm{kg} /$ minute, $95 \% \mathrm{Cl}-2.74$ to $3.35 ; 100$ participants, 4 trials; $\mathrm{I}^{2}=27 \%$ ) and Six-Minute Walk Test (MD $56.06 \mathrm{~min}, 95 \% \mathrm{Cl}-9.14$ to $121.26 ; 105$ participants, 4 trials; ${ }^{2}=64 \%$ ).

\section{Exploratory outcomes}

Physical exercise was not associated with beneficial or harmful effects on serum creatinine (MD $-1.54 \mu \mathrm{mol} / \mathrm{L}, 95 \% \mathrm{Cl}-8.03$ to 4.95 ; 99 participants, 4 trials; $\mathrm{I}^{2}=0 \%$; Analysis 1.13 ), serum albumin (MD $0.05 \mathrm{~g} / \mathrm{L}, 95 \% \mathrm{Cl}-1.48$ to $1.59 ; 155$ participants, 6 trials; $\mathrm{I}^{2}=9 \%$; Analysis 1.12), serum ammonia (MD $8.39 \mu \mathrm{mol} / \mathrm{L}, 95 \% \mathrm{Cl}-4.20$ to 20.97; 73 participants, 3 trials; $\mathrm{I}^{2}=0 \%$; Analysis 1.14 ), or blood glucose (MD $0.27 \mathrm{mmol} / \mathrm{L}, 95 \% \mathrm{Cl}-0.54$ to 1.08 ; 59 participants, 2 trials; $\mathrm{I}^{2}=0 \%$; Analysis 1.11).

\section{'Summary of findings' table}

As shown in the Summary of findings for the main comparison, we downgraded the quality of the evidence to low or very low because of 1 . within trial risk of bias (lack of trials at low risk of bias, one level); 2 . inconsistency (between trial heterogeneity 
identified although only four trials are included, one level); 3. serious imprecision (insufficient statistical power, one level).

\section{DISCUSSION}

\section{Summary of main results}

This review only included six RCTs with 173 participants diagnosed with Child-Pugh stage A or B cirrhosis. None of the included trials were low risk of bias in the overall assessment of bias control. Physical exercise for eight to 14 weeks did not appear to affect mortality or health-related quality of life compared with sham exercise or no exercise. Furthermore, physical exercise did not increase the risk of serious or non-serious adverse events. In addition, we found no effect of physical exercise on exercise capacity and the only beneficial effect on anthropometric assessments was detected when analysing mid-arm circumference.

\section{Overall completeness and applicability of evidence}

This review was based on a sample size of 173 participants with cirrhosis. The stage of cirrhosis was limited to Child-Pugh A and $B$. We found no trials involving decompensated participants with stage $C$ and it reduced some of the variations in the participants. However, the participants varied in gender, aetiology, duration of illness, age, comorbidity, etc. causing a biological diversity likely to affect responsiveness to treatment. We were unable to gather enough data to evaluate any effects caused by sex, aetiology, etc. We did not have sufficient data to assess potential differences in outcomes according to exercise regimen (type, duration, etc). Despite some heterogeneity in the participants and the interventions, we still considered the data applicable for our outcomes, especially important primary outcomes such as mortality and adverse events.

\section{Quality of the evidence}

We included RCTs, but no cross-sectional studies. This review identified several methodological concerns. Apart from an expected lack of blinding due to the nature of the intervention, the investigators were unblinded in some of the studies. Adding attribution bias and imprecision of outcomes due to small sample sizes, few events, and overlapping Cls (clinical heterogeneity), we downgraded the evidence for each of the primary, secondary, and exploratory analyses. For details, see Summary of findings for the main comparison.

We did not detect any missing data for mortality, serious adverse events, and non-serious events. All treatments of the participants were known to the investigators during the intervention. But for continuous follow-up data (e.g. quality of life, secondary, and exploratory outcomes) attribution bias may have occurred. Continuous data collection required physical attendance of the participants. The trials reported results from 'available-case data' and there were no statements of imputing the missing data with replacement values. We planned to evaluate the importance of missing data in a worst-case scenario analysis for dichotomous data. But we only found missing data for continuous data. We did not have access to all raw participant data set from the original investigators. Instead, we graded trials involved with a high risk of bias in the risk of bias tables (see 'Risk of bias' tables in the Characteristics of included studies table) and performed a sensitivity analysis for significant analyses.
In total, 18/173 (10\%) participants were lost to follow-up. Losses were equal among groups; eight participants from intervention groups and 10 from control groups (including the death of two participants). Several trials stated that these losses did not impact the baseline values, assuming that the participants lost to followup were equal in baseline values compared to the participants who completed the trials. This may minimise the potential confounding impact of the missing data, but we cannot state this for certain.

\section{Potential biases in the review process}

We attempted to minimise selection bias using the search strategy described in the Search methods for identification of studies section. We are confident, that we have not missed published trials, but we cannot exclude the possibility that we have missed unpublished trials or that small trials with negative results may not have been published as abstracts or full papers. Two of the review authors (LA and GD) conducted one of the included trials; however, another two review author (AR and LG) collected data from this trial (Aamann 2018).

\section{Agreements and disagreements with other studies or reviews}

One meta-analysis included 81 participants from four RCTs and found no evidence of effect of exercise in participants with cirrhosis (Brustia 2018). Several reviews without meta-analyses have been published (Toshikuni 2014; Shephard 2015; Berzigotti 2016b; Duarte-Rojo 2017). One review stated that regular moderate physical activity enhanced liver health, looking at all stages of liver disease, but there was a lack of RCTs that included participants with cirrhosis (Shephard 2015). Another review concluded that establishments for optimal exercise regimens for people with cirrhosis were required (Toshikuni 2014) and one review stated that in compensated cirrhosis exercise acutely elevates portal pressure, but is proven safe in the longer term and is probably beneficial (Berzigotti 2016b). One review from 2017 concluded that exercise combined with an nutritional intervention improved functional status and sarcopenia in end-stage liver disease in people awaiting a liver transplant and, based on available evidence, moderate-intensity exercise is safe for this population. They stated that it is not expected for people on a liver transplant list to have cardiovascular contraindications towards exercise (DuarteRojo 2017). All four reviews expected exercise to have a beneficial effect on factors included in this meta-analysis, but the data at the moment are too sparse to confirm this.

This review found no evidence to confirm or reject that exercise is unsafe for people with cirrhosis. Exercise has been considered a potentially life-threatening intervention for people with cirrhosis due to an acute effect on portal pressure that increases the risk of variceal bleeding (Bandi 1998; García-Pagàn 1998). One trial included in this review measured the HVPG (MacíasRodríguez 2016). Both groups received beta-blockers, but the HVPG significantly decreased in the intervention group after 14 weeks of moderate-intensive exercise comprising both aerobic and anaerobic training. Lifestyle intervention decreased the HVPG in 60 obese participants allocated to a home-exercising programme and diet (Berzigotti 2016a). This indicates that long-term exercise may not adversely affect HVPG, but this review cannot draw conclusions on the effect of exercise on HVPG. 
There was no clear effect of exercise on the risk of serious adverse events. Serious adverse events related to portal hypertension also involve ascites. One trial reported paracentesis in two exercising participants as a serious adverse event (Aamann 2018). Additionally, we reported other complications related to portal hypertension such as variceal bleeding, infections and hepatocellular carcinoma (Table 1). We do not consider the total amount of serious adverse events as abnormally elevated in these chronically ill participants. But the actual amount of evidence is not sufficient to draw a conclusion for people with cirrhosis Child-Pugh A or B.

Exercise did not have any effect on exercise capacity/physical fitness (peak oxygen uptake or Six-Minute Walk Test) or anthropometric measurements. This may be explained by the great diversity in the interventions. The exercise programmes differed considerably in intensity, method, duration, etc. As of 2018 , there is no consensus regarding the most effective exercise programme for chronically ill elderly people. The American College of Sports Medicines and American Heart Association's guideline for healthy older adults recommend moderate-intensity aerobic physical activity for a minimum of 30 minutes five days each week or vigorous intensity for a minimum of 20 minutes three days each week to promote and maintain health. To maintain or increase muscular strength and endurance, resistance training should be repeated twice each week (Nelson 2007). Whether these recommendations also correspond well to cirrhosis are yet unknown. One might speculate that the increased catabolic state in people with cirrhosis may require a more specialised exercise programme including nutritional guidance to reverse the loss of for example, muscle size and strength compared to healthy elderly people. In contrast, other chronically ill and cachectic patient groups have already proven it possible to enhance endurance and muscle strength (Clark 2000).

Body weight and BMI tended to be high in both groups. We could not extract general information on ascites etc., making it impossible to state whether overweight was due to overhydration, gain in muscle mass or, for example, fat. A high BMI may demonstrate that people with cirrhosis are not always undernourished, but frequently also develop obesity. Even so, sarcopenia still tends to be an underlying issue (Berzigotti 2016a).

Results from mid-arm circumference measurements showed that exercise may induce a larger circumference (low-quality evidence). Mid-arm circumference is a measurement for nutritional status, but does not predict the distribution of fat and muscle. Future review data on anthropometric measurements could benefit from including, for example, triceps skinfold and also calculations on mid-arm muscle circumference or area. This is illustrated by a trial reporting a significant decrease in mid-arm circumference when comparing the baseline and follow-up values in the intervention group, but an increase in mid-arm muscle circumference (Román 2016).

Surprisingly, there was no effect on quality of life. Quality of life is improved by physical exercise in other chronic diseases (e.g. chronic obstructive pulmonary disease; McCarthy 2015). The included trials individually reported effects of health status/quality of life (Román 2014; Zenith 2014; Aamann 2018), but mainly in subcategories and not total scores. The trials used different questionnaires, either disease-specific or generic. Due to this diversity, we chose not to compare overall results, but analyse results separately including fewer participants per analysis and weakening the power. Including more trials in the future may change the outcome.

In people with chronic obstructive pulmonary disease an improvement of $30 \mathrm{~min}$ in the Six-Minute Walk Test is considered sufficient to evaluate an efficacy in therapeutic interventions (Holland 2014). We found no beneficial effect of exercise using the Six-Minute Walk Test, but the MD between groups was 56 min (95\% Cl -9.14 to $121.26 ; \mathrm{P}=0.09)$. One trial had lower values of follow-up walking distance data when comparing the intervention group and control group (Krüger 2018), but looking at changes from baseline to follow-up, the intervention group improved their walking distance and the distance deteriorated in the control group. Inclusion of more studies is expected to improve the outcome.

In accordance, there was no certain effect on peak oxygen uptake. Aerobic capacity is impaired in people with compensated cirrhosis which affects mortality (Jones 2012; Bernal 2014). In individual trials, aerobic exercise improved peak oxygen uptake in people with cirrhosis (Campillo 1990b; Zenith 2014; Krüger 2018). People with coronary artery disease attending cardiac rehabilitation improved survival by improving cardiorespiratory fitness (Martin 2013).

\section{AUTHORS' CONCLUSIONS}

\section{Implications for practice}

We included six randomised clinical trials in this review. Despite a limited total number of included trials, this is to date the largest review concerning exercise and cirrhosis. There is currently insufficient evidence to determine the effects of physical exercise on all-cause mortality or serious adverse events. The effects on physical fitness and anthropomorphic measures are also uncertain due to insufficient evidence.

The review included a large proportion of participants with Child A cirrhosis. None of the included trials specifically included participants with sarcopenia or malnutrition. Future trials including more participants with reduced muscle strength/mass and participants with Child C cirrhosis are needed.

\section{Implications for research}

The evidence is insufficient and additional knowledge from larger randomised clinical trials is needed to estimate whether exercise has a clinically relevant effect on people with chronic liver disease.

We used the EPICOT format to describe the consequences of our review for research (Brown 2006).

Evidence (what is the current state of the evidence?): this review includes six randomised clinical trials and found low-quality evidence that physical exercise practised for eight to 14 weeks may have a beneficial, gaining effect on mid-arm circumference. The evidence concerning all-cause mortality, serious adverse events, and non-serious adverse events is insufficient.

Participants (what is the population of interest?): we evaluated people with cirrhosis Child-Pugh A and B.

Interventions (what are the interventions of interest?): physical exercise. 
Comparisons (what are the comparisons of interest?): placebo controlled including sham exercise (supervised relaxation) or no intervention.

Outcomes (what are the outcomes of interest?): all-cause mortality, serious adverse events, and quality of life. Additionally, we looked at anthropometrics measurements, physical function, and blood samples.

Time stamp (data of literature search): February 2018.

\section{ACK N O WLEDGEMENTS}

We thank Sarah Louise Klingenberg, Information Specialist at the Cochrane Hepato-Biliary Group, for her help with the search strategies for electronic searches.
Cochrane Review Group funding acknowledgement: the Danish State is the largest single founder of the Cochrane Hepato-Biliary Group through its investment in the Copenhagen Trial Unit, Centre for Clinical Intervention Research, Rigshospitalet, Copenhagen University Hospital, Denmark. Disclaimer: the views and opinions expressed in this review are those of the authors and do not necessarily reflect those of the Danish State or the Copenhagen Trial Unit.

Peer reviewers: Layli Eslami, Iran

Contact Editor: Brian Davidson, UK

Sign-off Editor: Christian Gluud, Denmark 


\section{RE F E R E N C E S}

\section{References to studies included in this review}

Aamann 2018 \{published and unpublished data\}

* Aamann L, Dam G, Borre M, Overgaard K, Andersen H, Vilstrup $\mathrm{H}$, et al. Resistance training improves muscle size and muscle strength in liver cirrhosis - a randomized controlled trial. Journal of Hepatology 2018;68(Suppl 1):S79. [DOI: 10.1016/ S0168-8278(18)30377-5; NCT02343653]

Krüger 2018 \{published data only (unpublished sought but not used)\}

Krüger $\mathrm{C}$. The effect of eight weeks of home based aerobic exercise training on peak exercise oxygen consumption, sixminute walk test distance, thigh muscle mass, and health related quality of life in Child Pugh class A and B cirrhosis patients, 2017. era.library.ualberta.ca/files/cbc386j51s (accessed 12 October 2018). [DOI: doi.org/10.7939/R30C4SZ83]

Krüger C, McNeely M, Bailey R, Yavari M, Abraldes J, Carbonneau $\mathrm{M}$, et al. Home exercise therapy is well tolerated and improves exercise capacity in patients with Child Pugh A and B cirrhosis, 2017. s3.amazonaws.com/media.guidebook.com/upload/ aHQdQSeZrebRtrdkzNP4zVt8ktcMUA5Tcrd6erKj/ Kuz7w5neY28FQkE3Z6urFfKt1a9UUH7UF7bx.pdf (accessed 12 October 2018).

* Krüger C, McNeely M, Bailey R, Yavari M, Abraldes J, Carbonneau $\mathrm{M}$, et al. Home exercise training improves exercise capacity in cirrhosis patients: role of exercise adherence. Scientific Reports 2018;8(1):99. [DOI: 10.1038/s41598-017-18320y; NCT02267421; PUBMED: 29311671]

Tandon P, Krüger C, Haykowsky M, McNeely M, Abraldes J, Carbonneau $\mathrm{M}$, et al. Home exercise therapy is well tolerated and improves exercise capacity in patients with Child Pugh $A$ and B cirrhosis. Abstract American College of Gastroenterology. 2016:S336. [DOI: dx.doi.org/10.1038/ajg.2016.359]

\section{Macías-Rodríguez 2016 \{published data only\}}

Macias-Rodriguez R, Torre A, Ilarraza-Lomeli H, Ruiz-Margain A, Garcia-Flores O, Duarte-Rojo A. Changes on hepatic venous pressure gradient induced by a physical exercise program in cirrhotic patients: a randomized open clinical trial. Hepatology (Baltimore, Md.) 2014;60(S1):246A-7A.

* Macías-Rodríguez R, Ilarraza-Lomelí H, Ruiz-Margáin A, Poncede-León-Rosales S, Vargas-Vorácková F, García-Flores O, et al. Changes in hepatic venous pressure gradient induced by physical exercise in cirrhosis: results of a pilot randomized open clinical trial. Clinical and Translational Gastroenterology 2016;7(7):e180-9. [NCT00517738; PUBMED: 27415618]

\section{Román 2014 \{published data only\}}

* Román E, Torrades MT, Nadal MJ, Cárdenas G, Nieto JC, Vidal S, et al. Randomized pilot study: effects of an exercise programme and leucine supplementation in patients with cirrhosis. Digestive Diseases and Sciences 2014;59(8):1966-75. [NCT01060813; PUBMED: 24599772]
Román E, Torrades T, García-Picart C, Herrera S, Marin AM, Doñate $M$, et al. Study by densitometry and ergospirometry of the effects of an exercise programme in patients with cirrhosis. Journal of Hepatology 2013;58(Suppl 1):S102. [DOI: 10.1016/ S0168-8278\%2813\%2960239-1; CN-01027430]

Soriano G, Roman E, Torrades MT, Cardenas G, Cordoba J, Nadal MJ, et al. Study of the benefit of an exercise programme and branched amino acid supplements in patients with liver cirrhosis [Spanish]. Trauma Fundacion Mapfre 2013;24(1):6-11.

Soriano G, Roman E, Torrades MT, Cardenas G, Cordoba J, Vidal S. Impact of an exercise programme on quality of life, effort tolerance and muscle mass in patients with cirrhosis. Journal of Hepatology 2011;54(Suppl 1):S81.

Román 2016 \{published data only\}

Román E, Garcia-Galcerán C, Torrades T, Herrera S, Marin A, Donate $\mathrm{M}$, et al. Effects of an exercise programme on functional capacity, body composition and risk of falls in patients with cirrhosis: a randomized clinical trial. PloS One 2016;11(3):e0151652-67. [NCT01447537; PUBMED: 27011355]

\section{Zenith 2014 \{published data only\}}

Zenith L, Haykowsky M, Ramadi A, Yavari M, Meena N, Harvey A, et al. Eight weeks of endurance exercise training improves aerobic capacity, muscle mass, and symptoms of fatigue in patients with Child-Pugh class $A$ and $B$ cirrhosis. Hepatology (Baltimore, Md.) 2013;58(S1):989A-90A. [DOI: dx.doi.org/10.1002/hep.26873; CN-01024214]

* Zenith L, Meena N, Ramadi A, Yavari M, Harvey A, Carbonneau $\mathrm{M}$, et al. Eight weeks of exercise training increases aerobic capacity and muscle mass and reduces fatigue in patients with cirrhosis. Clinical Gastroenterology and Hepatology 2014;12(11):1920-6.e2. [NCT01799785; PUBMED: 24768811]

\section{References to studies excluded from this review}

Berzigotti 2016a \{published data only\}

Berzigotti A, Albillos A, Villanueva C, Genescá J, Ardevol A, Augustín S, et al. Effects of an intensive lifestyle intervention program on portal hypertension in patients with cirrhosis and obesity: The SportDiet Study. Hepatology (Baltimore, Md.) 2016;65(4):1293-305. [DOI: 10.1002/hep.28992; 27997989]

\section{Campillo 1990b \{published data only\}}

Campillo B, Fouet P, Bonnet JC, Atlan G. Submaximal oxygen consumption in liver cirrhosis. Evidence of severe functional aerobic impairment. Journal of Hepatology 1990;10(2):163-7. [PUBMED: 2332586]

\section{Debette-Gratien 2014 \{published data only\}}

Debette-Gratien M, Tabouret T, Antonini MT, Dalmay F, Carrier P, Legros R, et al. Personalized adapted physical activity before liver transplantation: acceptability and results. Transplantation 2014;99(1):145-50. [DOI: 10.1097/TP.0000000000000245; PUBMED: 25531893] 


\section{Degoricija 2003 \{published data only\}}

Degoricija V, Zjacic-Rotkvic V, Marout J, Sefer S, Troskot B. Clinical and neurohumoral response to posture, physical exercise, and ascites treatment in Child-Pugh C liver cirrhosis: randomized prospective trial. Croatian Medical Journal 2003;44(2):178-86. [PUBMED: 12698509]

\section{Hiraoka 2017 \{published data only\}}

Hiraoka A, Michitaka K, Kiguchi D, Izumoto H, Ueki H, Kaneto M, et al. Efficacy of branched-chain amino acid supplementation and walking exercise for preventing sarcopenia in patients with liver cirrhosis. European Journal of Gastroenterology \& Hepatology 2017;29(12):1416-23. [DOI: 10.1097/MEG.0000000000000986]

\section{Konishi 2011 \{published data only\}}

Konishi I, Hiasa Y, Tokumoto Y, Abe M, Furukawa S, Toshimitsu K, et al. Aerobic exercise improves insulin resistance and decreases body fat and serum levels of leptin in patients with hepatitis C virus. Hepatology Research 2011;41(10):928-35. [PUBMED: 21707884]

\section{Nishida 2016 \{published data only\}}

Nishida Y, Ide Y, Okada M, Otsuka T, Eguchi Y, Ozaki I, et al. Effects of home-based exercise and branched-chain amino acid supplementation on aerobic capacity and glycemic control in patients with cirrhosis. Hepatology Research 2016;47(3):E193-200. [DOI: 10.1111/hepr.12748]

\section{Pattullo 2013 \{published data only\}}

Pattullo V, Duarte-Rojo A, Soliman W, Vargas-Vorackova F, Sockalingam S, Fantus IG, et al. A 24-week dietary and physical activity lifestyle intervention reduces hepatic insulin resistance in the obese with chronic hepatitis C. Liver International 2013;33:410-9. [PUBMED: 23278982]

\section{Ritland 1983 \{published data only\}}

Ritland S, Petlund CF, Knudsen T, Skrede S. Improvement of physical capacity after long-term training in patients with chronic active hepatitis. Scandinavian Journal of Gastroenterology 1983;18(8):1083-7. [PUBMED: 6673079]

\section{Additional references}

\section{Bandi 1998}

Bandi JC, García-Pagán JC, Escorsell A, Francois E, Moitinho E, Rodés J, et al. Effects of propranolol on the hepatic hemodynamic response to physical exercise in patients with cirrhosis. Hepatology (Baltimore, Md.) 1998;28(3):677-82. [PUBMED: 9731558]

\section{Bay Nielsen 2005}

Bay Nielsen H, Secher NH, Clemmesen O, Ott P. Maintained cerebral and skeletal muscle oxygenation during maximal exercise in patients with liver cirrhosis. Journal of Hepatology 2005;43(2):266-71. [PUBMED: 15975685]

\section{Bernal 2014}

Bernal W, Martin-Mateos R, Lipcsey M, Tallis C, Woodsford K, McPhail MJ, et al. Aerobic capacity during cardiopulmonary exercise testing and survival with and without liver transplantation for patients with chronic liver disease. Liver Transplantation 2014;20(1):54-62. [PUBMED: 24136710]

\section{Berzigotti 2016b}

Berzigotti A, Saran U, Dufour JF. Physical activity and liver diseases. Hepatology (Baltimore, Md.) 2016;63(3):1026-40. [PUBMED: 26313307]

\section{Biagini 2006}

Biagini MR, Tozzi A, Grippo A, Galli A, Milani S, Amantini A. Muscle fatigue in women with primary biliary cirrhosis: spectral analysis of surface electromyography. World Journal of Gastroenterology 2006;12(32):5186-90. [PUBMED: 16937530]

\section{Bolster 2004}

Bolster DR, Jefferson LS, Kimball SR. Regulation of protein synthesis associated with skeletal muscle hypertrophy by insulin-, amino acid- and exercise-induced signalling. Proceedings of the Nutrition Society 2004;63(2):351-6. [PUBMED: 15294054]

\section{Brown 2006}

Brown P, Brunnhuber K, Chalkidou K, Chalmers I, Clarke M, Fenton $\mathrm{M}$, et al. How to formulate research recommendations. BMJ (Clinical Research Ed.) 2006;333(7572):804-6. [PUBMED: 17038740]

\section{Brustia 2018}

Brustia B, Savier E, Scatton O. Physical exercise in cirrhotic patients: towards prehabilitation on waiting list for liver transplantation. A systematic review and meta-analysis. Clinics and Research in Hepatology and Gastroenterology 2018;42(3):205-15. [PUBMED: 29162460]

\section{Campillo 1990a}

Campillo B, Chapelain C, Bonnet JC, Frisdal E, Devanlay M, Bouissou $P$, et al. Hormonal and metabolic changes during exercise in cirrhotic patients. Metabolism 1990;39(1):18-24. [PUBMED: 2403618]

\section{Cerri 2010}

Cerri G, Cocchi CA, Montagna M, Zuin M, Podda M, Cavallari P, et al. Patients with primary biliary cirrhosis do not show post-exercise depression of cortical excitability. Clinical Neurophysiology 2010;121(8):1321-8. [PUBMED: 20363183]

\section{Clark 2000}

Clark CJ, Cochrane LM, Mackay E, Paton B. Skeletal muscle strength and endurance in patients with mild COPD and the effects of weight training. European Respiratory Journal 2000;15:92-7. [PUBMED: 10678627]

\section{Córdoba 2008}

Córdoba J, Mínguez B. Hepatic encephalopathy. Seminars in Liver Disease 2008;28(1):70-80. [PUBMED: 18293278]

\section{Córdoba 2014}

Córdoba J, Ventura-Cots M, Simón-Talero M, Amorós A, Pavesi M, Vilstrup H, et al. Characteristics, risk factors, and mortality of cirrhotic patients hospitalized for hepatic 
encephalopathy with and without acute-on-chronic liver failure (ACLF). Journal of Hepatology 2014;60(2):275-81. [PUBMED: 24128414]

\section{D'Amico 1986}

D'Amico G, Morabito A, Pagliaro L, Marubini E. Survival and prognostic indicators in compensated and decompensated cirrhosis. Digestive Diseases and Sciences 1986;31(5):468-75. [PUBMED: 3009109]

\section{D'Amico 2006}

D'Amico G, Garcia-Tsao G, Pagliaro L. Natural history and prognostic indicators of survival in cirrhosis: a systematic review of 118 studies. Journal of Hepatology 2006;44(1):217-31. [PUBMED: 16298014]

\section{Dam 2011}

Dam G, Keiding S, Munk OL, Ott P, Buhl M, Vilstrup H, et al. Branched-chain amino acids increase arterial blood ammonia in spite of enhanced intrinsic muscle ammonia metabolism in patients with cirrhosis and healthy subjects. American Journal of Physiology 2011;301(2):G269-77. [PUBMED: 21636533]

\section{Dasarathy 2012}

Dasarathy S. Consilience in sarcopenia of cirrhosis. Journal of Cachexia, Sarcopenia and Muscle 2012;3(4):225-37. [PUBMED: 22648736]

\section{de Jongh 1992}

de Jongh FE, Janssen HL, de Man RA, Hop WC, Schalm SW, van Blankenstein M. Survival and prognostic indicators in hepatitis B surface antigen-positive cirrhosis of the liver. Gastroenterology 1992;103(5):1630-5. [PUBMED: 1426884]

\section{Duarte-Rojo 2017}

Duarte-Rojo A, Ruiz-Margain A, Montano-Loza AJ, MaciasRodriguez RU, Ferrando A, Kim WR. Exercise and physical activity for patients with end-stage liver disease: Improving functional status and sarcopenia while on the transplant waiting list. Liver Transplantation 2017;24:122-39. [PUBMED: 29024353]

\section{Egger 1997}

Egger M, Davey Smith G, Schneider M, Minder C. Bias in metaanalysis detected by a simple, graphical test. BMJ (Clinical Research Ed.) 1997;315(7109):629-34. [PUBMED: 9310563]

\section{Faustini-Pereira 2015}

Faustini-Pereira JL, Homercher-Galant L, Garcia E, de Mello Brandão AB, Marroni CA. Exercise capacity of cirrhotic patients with hepatopulmonary syndrome. Annals of Hepatology 2015;14(3):361-8. [PUBMED: 25864217]

\section{Galant 2012}

Galant LH, Forgiarini LA Jr, Dias AS, Marroni CA. Functional status, respiratory muscle strength, and quality of life in patients with cirrhosis. Revista Brasileira de Fisioterapia 2012;16(1):30-4. [PUBMED: 22441225]

\section{Galant 2013}

Galant LH, Forgiarini LA Jr, Dias AS, Marroni CA. Maximum oxygen consumption predicts mortality in patients with alcoholic cirrhosis. Hepato-gastroenterology 2013;60(125):1127-30. [PUBMED: 23425809]

\section{García-Pagàn 1998}

García-Pagàn JC, Santos C, Barbera JA, Luca A, Roca J, Rodrigues-Roisin, et al. Physical exercise increases portal pressure in patients with cirrhosis and portal hypertension. Gastroenterology 1998;111(5):1300-6. [PUBMED: 8898644]

\section{Goswami 2014}

Goswami A, Bhargava N, Dadhich S, Kulamarva G. Insulin resistance in euglycemic cirrhosis. Annals of Gastroenterology 2014;27(3):237-43. [PUBMED: 24974878]

\section{GRADEpro [Computer program]}

McMaster University (developed by Evidence Prime). GRADEpro GDT. Version accessed 31 May 2017. Hamilton (ON): McMaster University (developed by Evidence Prime), 2015.

\section{Guyatt 2008}

Guyatt GH, Oxman AD, Vist GE, Kunz R, Falck-Ytter Y, AlonsoCoello $P$, et al. GRADE: an emerging consensus on rating quality of evidence and strength of recommendations. BMJ (Clinical Research Ed.) 2008;336(7650):924-6. [PUBMED: 18436948]

\section{Harbord 2006}

Harbord RM, Egger M, Sterne JA. A modified test for smallstudy effects in meta-analyses of controlled trials with binary endpoints. Statistics in Medicine 2006;25(20):3443-57. [PUBMED: 16345038]

\section{Hayashi 2012}

Hayashi F, Momoki C, Yuikawa M, Simotani Y, Kawamura E, Hagihara $A$, et al. Nutritional status in relation to lifestyle in patients with compensated viral cirrhosis. World Journal of Gastroenterology 2012;18(40):5759-70. [PUBMED: 23155318]

\section{Hayashi 2013}

Hayashi F, Matsumoto Y, Momoki C, Yuikawa M, Okada G, Hamakawa E, et al. Physical inactivity and insufficient dietary intake are associated with the frequency of sarcopenia in patients with compensated viral liver cirrhosis. Hepatology Research 2013;43:1264-75. [PUBMED: 23489325]

\section{Hellberg 2014}

Hellberg M, Wiberg EM, Simonsen O, Höglund P, Clyne N. Small distal muscles and balance predict survival in end-stage renal disease. Nephron. Clinical Practice 2014;126(3):116-23. [PUBMED: 24713811]

\section{Higgins 2008}

Higgins JP, White IR, Wood AM. Imputation methods for missing outcome data in meta-analysis of clinical trials. Clinical Trials 2008;5(3):225-39. [PUBMED: 18559412] 


\section{Higgins 2011}

Higgins JP, Whitehead A, Simmonds M. Sequential methods for random-effects meta-analysis. Statistics in Medicine 2011;30(9):903-21. [PUBMED: 21472757]

\section{Holland 2014}

Holland AE, Spruit MA, Troosters T, Puhan MA, Pepin V, Saey D, et al. An official European Respiratory Society/American Thoracic Society technical standard: field walking tests in chronic respiratory disease. European Respiratory Journal 2014;44(6):1428-46. [PUBMED: 25359355]

\section{Hollingsworth 2008}

Hollingsworth KG, Newton JL, Taylor R, McDonald C, Palmer JM, Blamire AM, et al. Pilot study of peripheral muscle function in primary biliary cirrhosis: potential implications for fatigue pathogenesis. Clinical Gastroenterology and Hepatology 2008;6(9):1041-8. [PUBMED: 18691944]

\section{Hollingsworth 2010}

Hollingsworth KG, Newton JL, Robinson L, Taylor R, Blamire AM, Jones DE. Loss of capacity to recover from acidosis in repeat exercise is strongly associated with fatigue in primary biliary cirrhosis. Journal of Hepatology 2010;53(1):155-61. [PUBMED: 20447719]

\section{Hróbjartsson 2001}

Hróbjartsson A, Gøtzsche PC. Is the placebo powerless? An analysis of clinical trials comparing placebo with no treatment. New England Journal of Medicine 2001;344(21):1594-602. [PUBMED: 11372012]

\section{ICH-GCP 1997}

International Conference on Harmonisation Expert Working Group. International Conference on Harmonisation of technical requirements for registration of pharmaceuticals for human use. ICH harmonised tripartite guideline. Guideline for good clinical practice CFR \& ICH Guidelines. Vol. 1, Philadelphia (PA): Barnett International/PAREXEL, 1997.

\section{Jones 2012}

Jones JC, Coombes JS, Macdonald GA. Exercise capacity and muscle strength in patients with cirrhosis. Liver Transplantation 2012;18(2):146-51. [PUBMED: 22139897]

\section{Lavie 2011}

Lavie CJ, Church TS, Milani RV, Earnest CP. Impact of physical activity, cardiorespiratory fitness, and exercise training on markers of inflammation. Journal of Cardiopulmonary Rehabilitation and Prevention 2011;31(3):137-45. [PUBMED: 21427600]

\section{Lemyze 2011}

Lemyze $M$, Dharancy $S$, Nevière R, Wallaert B. Cardiopulmonary response to exercise in patients with liver cirrhosis and impaired pulmonary gas exchange. Respiratory Medicine 2011;105(10):1550-6. [PUBMED: 21764574]

\section{Lemyze 2013}

Lemyze M, Dharancy S, Wallaert B. Response to exercise in patients with liver cirrhosis: implications for liver transplantation. Digestive and Liver Disease 2013;45(5):362-6. [PUBMED: 23137795]

\section{Marchesini 2001}

Marchesini G, Bianchi G, Amodio P, Salerno F, Merli M, Panella C, et al. Factors associated with poor health-related quality of life of patients with cirrhosis. Gastroenterology 2001;120(1):170-8. [PUBMED: 11208726]

\section{Martin 2013}

Martin B, Arena R, Haykowsky M, Hauer T, Austford LD, Knudtson M, et al. Cardiovascular fitness and mortality after contemporary cardiac rehabilitation. Mayo Clinic Proceedings 2013;88(5):455-63. [PUBMED: 23639499]

\section{McCarthy 2015}

McCarthy B, Casey D, Devane D, Murphy K, Murphy E, Lacasse Y. Pulmonary rehabilitation for chronic obstructive pulmonary disease. Cochrane Database of Systematic Reviews 2015, Issue 2. [DOI: 10.1002/14651858.CD003793.pub3; PUBMED: 25705944]

\section{McLean 2014}

McLean RR, Shardell MD, Alley DE, Cawthon PM, Fragala MS, Harris TB, et al. Criteria for clinically relevant weakness and low lean mass and their longitudinal association with incident mobility impairment and mortality: the foundation for the National Institutes of Health (FNIH) sarcopenia project. Journals of Gerontology. Series A, Biological Sciences and Medical Sciences 2014;69(5):576-83. [PUBMED: 24737560]

\section{Meza-Junco 2013}

Meza-Junco J, Montano-Loza AJ, Baracos VE, Prado CM, Bain VG, Beaumont C, et al. Sarcopenia as a prognostic index of nutritional status in concurrent cirrhosis and hepatocellular carcinoma. Journal of Clinical Gastroenterology 2013;47(10):861-70. [PUBMED: 23751844]

\section{Mikines 1989}

Mikines KJ, Sonne B, Tronier B, Galbo H. Effects of acute exercise and detraining on insulin action in trained men. Journal of Applied Physiology 1989;66(2):704-11. [PUBMED: 2496077]

\section{Mokdad 2014}

Mokdad AA, Lopez AD, Shahraz S, Lozano R, Mokdad AH, Stanaway J, et al. Liver cirrhosis mortality in 187 countries between 1980 and 2010: a systematic analysis. BMC Medicine 2014;12:145. [PUBMED: 4169640]

\section{Montano-Loza 2012}

Montano-Loza AJ, Meza-Junco J, Prado CM, Lieffers JR, Baracos VE, Bain VG, et al. Muscle wasting is associated with mortality in patients with cirrhosis. Clinical Gastroenterology and Hepatology 2012;10(2):166-73.e1. [PUBMED: 21893129]

\section{Montano-Loza 2013}

Montano-Loza AJ. New concepts in liver cirrhosis: clinical significance of sarcopenia in cirrhotic patients. Minerva Gastroenterologica e Dietologica 2013;59(2):173-86. [PUBMED: 23831908] 


\section{Montano-Loza 2014}

Montano-Loza AJ. Clinical relevance of sarcopenia in patients with cirrhosis. World Journal of Gastroenterology 2014;20(25):8061-71. [PUBMED: 25009378]

\section{Mori 2007}

Mori T, Nomura M, Hori A, Kondo N, Bando S, Ito S. Mechanism of ST segment depression during exercise tests in patients with liver cirrhosis. Journal of Medical Investigation 2007;54(1-2):109-15. [PUBMED: 17380021]

\section{Morrison 1990}

Morrison WL, Bouchier IA, Gibson JN, Rennie MJ. Skeletal muscle and whole-body protein turnover in cirrhosis. Clinical Science 1990;78(6):613-9. [PUBMED: 2165895]

\section{Nelson 2007}

Nelson ME, Rejeski WJ, Blair SN, Duncan PW, Judge JO, King AC, et al. Physical activity and public health in older adults recommendation from the American College of Sports Medicine and the American Heart Association. Circulation 2007;116(9):1094. [PUBMED: 17671236]

\section{NIH 2006}

National Institutes of Health, National Heart, Lung, and Blood Institute. Your guide to physical activity and your heart. 2006. www.nhlbi.nih.gov/files/docs/public/heart/phy_active.pdf (accessed 13 January 2016).

\section{Periyalwar 2012}

Periyalwar P, Dasarathy S. Malnutrition in cirrhosis: contribution and consequences of sarcopenia on metabolic and clinical responses. Clinics in Liver Disease 2012;16(1):95-131. [PUBMED: 22321468]

\section{Polletta 2015}

Polletta L, Vernucci E, Carnevale I, Arcangeli T, Rotili D, Palmerio S, et al. SIRT5 regulation of ammonia-induced autophagy and mitophagy. Autophagy 2015;11(2):253-70. [PUBMED: 25700560]

\section{Premaratna 2002}

Premaratna R, Sathishchandra H, Thilakaratna Y, Shantharaj W, de Silva HJ. Effects of propranolol and nitrates on exercise capacity, respiratory minute volume and capillary oxygen saturation during exercise in cirrhotic patients with portal hypertension. Hepatology Research 2002;24(2):152-8. [PUBMED: 12270744]

\section{Puhan 2013}

Puhan MA, Siebeling L, Zoller M, Muggensturm P, ter Riet G. Simple functional performance tests and mortality in COPD. European Respiratory Journal 2013;42(4):956-63. [PUBMED: 23520321]

\section{Review Manager 2014 [Computer program]}

Nordic Cochrane Centre, The Cochrane Collaboration. Review Manager 5 (RevMan). Version 5.3. Copenhagen: Nordic Cochrane Centre, The Cochrane Collaboration, 2014.

\section{Royle 2003}

Royle P, Milne R. Literature searching for randomized controlled trials used in Cochrane reviews: rapid versus exhaustive searches. International Journal of Technology Assessment in Health Care 2003;19(4):591-603. [PUBMED: 15095765]

\section{Saunders 1981}

Saunders JB, Walters JR, Davies AP, Paton A. A 20-year prospective study of cirrhosis. British Medical Journal (Clinical Research Ed.) 1981;282(6260):263-6. [PUBMED: 6779978]

\section{Savović 2012}

Savović J, Jones H, Altman D, Harris R, Jüni P, Pildal J, et al. Influence of reported study design characteristics on intervention effect estimates from randomised controlled trials: combined analysis of meta-epidemiological studies. Health Technology Assessments 2012;16(35):1-82. [PUBMED: 22989478]

\section{Scaglione 2015}

Scaglione S, Kliethermes S, Cao G, Shoham D, Durazo R, Luke A, et al. The epidemiology of cirrhosis in the United States: a population-based study. Journal of Clinical Gastroenterology 2015;49(8):690-6. [PUBMED: 25291348]

\section{Shephard 2015}

Shephard RJ, Johnson N. Effects of physical activity upon the liver. European Journal of Applied Physiology 2015;115(1):1-46. [PUBMED: 25366252]

\section{Sinniah 1970}

Sinniah D, Fulton TT, McCullough $\mathrm{H}$. The effect of exercise on the venous blood ammonium concentration in man. Journal of Clinical Pathology 1970;23(8):715-9. [PUBMED: 5488045]

\section{Stata 14 [Computer program]}

Stata Corp. Stata. Version 14. College Station (TX): Stata Corp, 2007.

\section{Thiele 2013}

Thiele M, Askgaard G, Timm HB, Hamberg O, Gluud LL. Predictors of health-related quality of life in outpatients with cirrhosis: results from a prospective cohort. Hepatitis Research and Treatment 2013;2013:479639. [PUBMED: 24490061]

\section{Thorlund 2011}

Thorlund K, Engstrøm J, Wetterslev J, Brok J, Imberger G, Gluud C. User manual for Trial Sequential Analysis (TSA), 2011. ctu.dk/tsa/files/tsa_manual.pdf (accessed 23 April 2013).

\section{Toshikuni 2014}

Toshikuni N, Arisawa T, Tsutsumi M. Nutrition and exercise in the management of liver cirrhosis. World Journal of Gastroenterology 2014;20(23):7286-97. [PUBMED: 24966599]

\section{TSA 2011 [Computer program]}

Copenhagen Trial Unit. TSA - Trial Sequential Analysis. Version 0.9.5.10 Beta. Copenhagen: Copenhagen Trial Unit, 2011.

\section{Tsien 2013}

Tsien C, Shah SN, McCullough AJ, Dasarathy S. Reversal of sarcopenia predicts survival after a transjugular intrahepatic 
portosystemic stent. European Journal of Gastroenterology \& Hepatology 2013;25(1):85-93. [PUBMED: 23011041]

\section{Wetterslev 2017}

Wetterslev J, Jakobsen JC, Gluud C. Trial Sequential Analysis in systematic reviews with meta-analysis. BMC Medical Research Methodology 2017;17(1):39.

\section{Wong 2001}

Wong F, Girgrah N, Graba J, Allidina Y, Liu P, Blendis L. The cardiac response to exercise in cirrhosis. Gut 2001;49(2):268-75. [PUBMED: 11454805]

\section{Woo 2015}

Woo J, Leung J, Morley JE. Defining sarcopenia in terms of incident adverse outcomes. Journal of the American Medical Directors Association 2015;16(3):247-52. [PUBMED: 25548028]

\section{CHARACTERISTICS OF STUDIES}

Characteristics of included studies [ordered by study ID]

\section{Zatoński 2010}

Zatoński WA, Sulkowska U, Mańczuk M, Rehm J, Boffetta P, Lowenfels $A B$, et al. Liver cirrhosis mortality in Europe, with special attention to Central and Eastern Europe. European Addiction Research 2010;16(4):193-201. [PUBMED: 20606444]

\section{References to other published versions of this review} Aamann 2017

Aamann L, Dam G, Rinnov A, Vilstrup H, Gluud LL. Physical exercise for people with cirrhosis. Cochrane Database of Systematic Reviews 2017, Issue 6. [DOI: 10.1002/14651858.CD012678]

* Indicates the major publication for the study

Aamann 2018

\begin{tabular}{ll}
\hline Methods & Randomised, outpatient, open, parallel-arm trial \\
\hline Participants & 39 participants with cirrhosis. Baseline data for 39 participants (intervention 20; control 19) \\
Participant characteristics (mean \pm standard deviation or $\%$ ) \\
- Age: intervention $61.7 \pm 7.8$; control $63.0 \pm 7.0$ years \\
- Men: intervention $80 \%$; control $80 \%$ \\
- Child-Pugh A/B/C: intervention $50 \% / 50 \% / 0 \%$; control $52.6 \% / 47.4 \% / 0 \%$ \\
- Model of End-Stage Liver Disease score: intervention $10.8 \pm 2.7 ;$ control $10.7 \pm 2.8$ \\
- Body mass index: intervention $26.9 \pm 3.0$; control $25 \pm 4.2 \mathrm{~kg} / \mathrm{m}^{2}$ \\
Aetiology \\
- Alcohol: intervention $80 \%$; control $78.9 \%$ \\
- Chronic hepatitis C: intervention $5 \%$; control $10.5 \%$ \\
- NASH: intervention $5 \%$; control $0 \%$
\end{tabular}

Interventions

Intervention: 60-minute sessions of resistance training. A Masters student of Sport Science and a physician supervised all sessions.

Control: no intervention.

Cointervention: standard protein diet (1.2-1.5 g/kg/day). All participants received advice from a dietician and filled out a protein diary.

Duration: 12 weeks

\begin{tabular}{ll}
\hline Outcomes & Mortality, adverse events (serious and non-serious), 6MWT, QoL, blood test, and nutritional status \\
\hline Country & Denmark \\
\hline Inclusion period & January 2015 to October 2017 \\
\hline Publication status & Full-paper article (in submission) \\
\hline
\end{tabular}


Aamann 2018 (Continued)

Notes

The lead author of this review is the primary investigator of the trial; 2 review authors who were not involved in the trial (LG and AR) undertook the bias assessment of this trial.

\section{Risk of bias}

\begin{tabular}{|c|c|c|}
\hline Bias & Authors' judgement & Support for judgement \\
\hline $\begin{array}{l}\text { Random sequence genera- } \\
\text { tion (selection bias) }\end{array}$ & Low risk & Computer-generated random numbers \\
\hline $\begin{array}{l}\text { Allocation concealment } \\
\text { (selection bias) }\end{array}$ & Low risk & Sequentially numbered opaque sealed envelopes \\
\hline $\begin{array}{l}\text { Blinding of participants } \\
\text { and personnel (perfor- } \\
\text { mance bias) } \\
\text { All outcomes }\end{array}$ & High risk & Open trial without blinding of participants or personnel \\
\hline $\begin{array}{l}\text { Blinding of outcome as- } \\
\text { sessment (detection bias) } \\
\text { All outcomes }\end{array}$ & High risk & $\begin{array}{l}\text { Open trial without blinding of all outcome assessments (blinded assessment } \\
\text { of bioimpedance, anthropometric measurements, QoL, blood samples, 6MWT) }\end{array}$ \\
\hline $\begin{array}{l}\text { Incomplete outcome data } \\
\text { (attrition bias) } \\
\text { All outcomes }\end{array}$ & High risk & $\begin{array}{l}5 \text { participants were lost to follow-up ( } 1 \text { exercise; } 2 \text { controls; } 2 \text { controls died). } \\
\text { Only participants who completed were included the analysis according to } \\
\text { group allocation. }\end{array}$ \\
\hline $\begin{array}{l}\text { Selective reporting (re- } \\
\text { porting bias) }\end{array}$ & Low risk & $\begin{array}{l}\text { Clinically relevant outcomes were defined and described. Primary outcomes } \\
\text { listed in the trial registration (in ClinicalTrials.gov) corresponded to the out- } \\
\text { comes listed in the unpublished paper (available to the review authors). }\end{array}$ \\
\hline For-profit funding & Low risk & No for-profit funding \\
\hline Other bias & Low risk & No other biases identified \\
\hline $\begin{array}{l}\text { Overall risk of bias assess- } \\
\text { ment (non-mortality out- } \\
\text { comes) }\end{array}$ & High risk & High risk of bias \\
\hline $\begin{array}{l}\text { Overall risk of bias assess- } \\
\text { ment (mortality) }\end{array}$ & Low risk & Low risk of bias \\
\hline
\end{tabular}

Krüger 2018

\begin{tabular}{ll}
\hline Methods & Randomised, outpatient, open, parallel-arm trial \\
\hline Participants & 40 participants with cirrhosis. Baseline data for 40 participants (intervention 20; control 20) \\
& Participant characteristics (mean \pm standard deviation or $\%)$ \\
- Age: intervention $53.0 \pm 8.3$; control $56.4 \pm 8.5$ years \\
- Men: intervention $50 \%$; control $64 \%$ \\
- Child-Pugh A/B/C: intervention $70 \% / 30 \% / 0 \%$; control $70 \% / 30 \% / 0 \%$ \\
- Model of End-Stage Liver Disease score: intervention $9.05 \pm 2.61 ;$ control $9.71 \pm 3.16$ \\
- Body mass index: intervention $28.9 \pm 5.1$; control $28.9 \pm 4.2 \mathrm{~kg} / \mathrm{m}^{2}$ \\
Aetiology
\end{tabular}


Krüger 2018 (Continued)

- Alcohol: intervention 25\%; control 30\%

- Chronic hepatitis C: intervention 35\%; control 25\%

- NASH: intervention $25 \%$; control $25 \%$

Interventions

Intervention: home-based cycle endurance exercise training with a moderate-to-high intensity (heart rate $60-80 \%$ peak oxygen uptake) for 3 days per week. An exercise specialist supervised a training session once every 2 weeks and had regular telephone contact between these sessions.

Control: usual care

Duration: 8 weeks

\begin{tabular}{ll}
\hline Outcomes & $\begin{array}{l}\text { Mortality, adverse events (serious and non-serious), thigh circumference, peak oxygen uptake, ultra- } \\
\text { sound, creatinine, QoL, and 6MWT }\end{array}$ \\
\hline Country & Canada \\
\hline Inclusion period & January 2014 to January 2015 \\
\hline Publication status & Full-paper article \\
\hline Notes & Professor Tandon (ptandon@ualberta.ca) supplied additional information.
\end{tabular}

\section{Risk of bias}

\begin{tabular}{|c|c|c|}
\hline Bias & Authors' judgement & Support for judgement \\
\hline $\begin{array}{l}\text { Random sequence genera- } \\
\text { tion (selection bias) }\end{array}$ & Low risk & Computer-generated random numbers \\
\hline $\begin{array}{l}\text { Allocation concealment } \\
\text { (selection bias) }\end{array}$ & Low risk & Sequentially numbered opaque sealed envelopes \\
\hline $\begin{array}{l}\text { Blinding of participants } \\
\text { and personnel (perfor- } \\
\text { mance bias) } \\
\text { All outcomes }\end{array}$ & High risk & Open trial without blinding of participants or personnel \\
\hline $\begin{array}{l}\text { Blinding of outcome as- } \\
\text { sessment (detection bias) } \\
\text { All outcomes }\end{array}$ & High risk & $\begin{array}{l}\text { Open trial without blinding of all outcome assessments (the assessor measur- } \\
\text { ing the second thigh circumference and ultrasound thickness was blinded to } \\
\text { the prior measurements). }\end{array}$ \\
\hline $\begin{array}{l}\text { Incomplete outcome data } \\
\text { (attrition bias) } \\
\text { All outcomes }\end{array}$ & High risk & $\begin{array}{l}3 \text { participants were lost to follow-up ( } 1 \text { exerciser, } 2 \text { controls) and excluded } \\
\text { from the analyses. }\end{array}$ \\
\hline $\begin{array}{l}\text { Selective reporting (re- } \\
\text { porting bias) }\end{array}$ & Low risk & $\begin{array}{l}\text { Clinically relevant outcomes were defined and described in the trial registra- } \\
\text { tion and abstract. }\end{array}$ \\
\hline For-profit funding & Low risk & No for-profit funding \\
\hline Other bias & Low risk & No other biases identified \\
\hline $\begin{array}{l}\text { Overall risk of bias assess- } \\
\text { ment (non-mortality out- } \\
\text { comes) }\end{array}$ & High risk & High risk of bias \\
\hline
\end{tabular}


Krüger 2018 (Continued)

Overall risk of bias assess- Low risk Low risk of bias ment (mortality)

Macías-Rodríguez 2016

\begin{tabular}{|c|c|}
\hline Methods & Randomised, outpatient, open, parallel-arm trial \\
\hline \multirow[t]{7}{*}{ Participants } & $\begin{array}{l}29 \text { participants with cirrhosis recruited from outpatient clinics at } 2 \text { tertiary care centres. Baseline data } \\
\text { for } 25 \text { participants (intervention 13; control 12). }\end{array}$ \\
\hline & Participant characteristics (mean \pm standard deviation or $\%$ ) \\
\hline & - Age: intervention $53 \pm 1.48$; control $51 \pm 4.44$ years \\
\hline & - Men: intervention $69.2 \%$; control $83.3 \%$ \\
\hline & $\begin{array}{l}\text { - Model of End-Stage Liver Disease score (median and interquartile range): intervention } 9 \pm 2.96 \text {; control } \\
12 \pm 4.44\end{array}$ \\
\hline & - Child-Pugh score: intervention $6 \pm 0.74$; control $6 \pm 0.74$ \\
\hline & - Body mass index: intervention $27.5 \pm 0.81$; control $27.4 \pm 1.55 \mathrm{~kg} / \mathrm{m}^{2}$ \\
\hline
\end{tabular}

\section{Aetiology}

- Alcohol: intervention 7.7\%; control $16.7 \%$

- Chronic hepatitis C: intervention 38.5\%; control 25.0\%

- NASH: intervention $23.1 \%$; control $33.3 \%$

Intervention: nurses, physical therapists, and cardiologist supervised the physical exercise programme. The programme consisted of 40 sessions of aerobic training and kinesiotherapy (resistance/stretching) 3 times weekly. Aerobic exercise: 40 minutes on heart rate biofeedback workload cycloergometer (warm up 10 minutes, main phase 20 minutes, and cool down 10 minutes). Kinesiotherapy: 30 minutes of rhythmic activities.

Control: no intervention

Cointervention: nutritional therapy, beta-blockers

Duration: 14 weeks

Mortality, adverse events (serious and non-serious), QoL, exercise capacity, HVPG, and nutritional sta-
tus.
tus.

\begin{tabular}{ll}
\hline Country & Mexico \\
\hline Inclusion period & March 2009 to March 2014 \\
\hline
\end{tabular}

Publication status $\quad$ Full-paper article

Notes Additional information about the design and outcomes received via email from Dr Macías-Rodríguez.

2 participants from the intervention group developed gastrointestinal complications and 1 developed severe hypertension. 1 participant in the control group continued to drink alcohol and was, therefore, unable to continue in the trial.

\section{Risk of bias}


Macías-Rodríguez 2016 (Continued)

Random sequence genera- Low risk Computer-generated random numbers
tion (selection bias)

Allocation concealment Low risk Sequentially numbered opaque sealed envelopes
(selection bias)

Blinding of participants High risk Open trial without blinding of participants or personnel

and personnel (perfor-

mance bias)

All outcomes

\begin{tabular}{|c|c|c|}
\hline $\begin{array}{l}\text { Blinding of outcome as- } \\
\text { sessment (detection bias) } \\
\text { All outcomes }\end{array}$ & High risk & Open trial without blinding (portal pressure measurements blinded) \\
\hline $\begin{array}{l}\text { Incomplete outcome data } \\
\text { (attrition bias) } \\
\text { All outcomes }\end{array}$ & High risk & $\begin{array}{l}29 \text { participants were included and randomised. } 4 \text { participants did not receive } \\
\text { any intervention (excluded at baseline due to silent cardiac ischaemia (inter- } \\
\text { vention } 1 \text {; control } 2 \text { ) or lost to follow-up immediately after randomisation (in- } \\
\text { tervention } 1 \text { )). The remaining participants (intervention 13; control 12) were } \\
\text { accounted for. All receiving at least } 1 \text { day of intervention included in analyses. } \\
\text { Primary outcome (HVPG) was also analysed as per-protocol including all com- } \\
\text { pleting the protocol (intervention } 11 \text {; control } 11 \text { ). }\end{array}$ \\
\hline
\end{tabular}

\begin{tabular}{ll}
\hline $\begin{array}{l}\text { Selective reporting (re- } \\
\text { porting bias) }\end{array}$ & Low risk
\end{tabular}$\quad \begin{aligned} & \text { Clinically relevant outcomes were defined and described. The primary out- } \\
& \text { comes listed in the trial registration (in ClinicalTrials.gov) corresponded to the } \\
& \text { outcomes listed in the paper. }\end{aligned}$

For-profit funding Low risk Received funding from the National Council of Science and Technology (Con-
sejo Nacional de Ciencia y Tecnología, CONACYT) Mexico and the "Angeles Espinosa Yglesias" Award 2009 from FUNSALUD/FUNDHEPA, México.

\begin{tabular}{lll}
\hline Other bias & Low risk & No other biases identified \\
\hline $\begin{array}{l}\text { Overall risk of bias assess- } \\
\text { ment (non-mortality out- } \\
\text { comes) }\end{array}$ & High risk & High risk of bias \\
\hline $\begin{array}{l}\text { Overall risk of bias assess- } \\
\text { ment (mortality) }\end{array}$ & Low risk & Low risk of bias \\
\hline
\end{tabular}

\section{Román 2014}

\begin{tabular}{|c|c|}
\hline Methods & Randomised, outpatient, open, parallel-arm trial \\
\hline \multirow[t]{8}{*}{ Participants } & $\begin{array}{l}\text { Trial recruited } 20 \text { participants with cirrhosis from an outpatient clinic at a tertiary hospital. Baseline da- } \\
\text { ta for } 17 \text { participants (intervention } 8 \text {; control 9). }\end{array}$ \\
\hline & Participant characteristics (mean \pm standard deviation or $\%$ ) \\
\hline & - Age: intervention $65.5 \pm 6.5$; control $61 \pm 8$ years \\
\hline & - Men: intervention $62.5 \%$; control $77.8 \%$ \\
\hline & - Model of End-Stage Liver Disease score: intervention $9.5 \pm 1.25$; control $9 \pm 1.5$ \\
\hline & - Child-Pugh A/B/C: intervention 87\%/13\%/0\%; control 78\%/22\%/0\% \\
\hline & - Body mass index: intervention $26.7 \pm 19.4$; control $27.6 \pm 15.8 \mathrm{~kg} / \mathrm{m}^{2}$ \\
\hline & Aetiology \\
\hline
\end{tabular}


Román 2014 (Continued)

- Alcoholic liver disease: intervention $75 \%$; control $77.8 \%$

- Viral hepatitis: intervention $25 \%$; control $22.2 \%$

- NASH: intervention $0 \%$; control $0 \%$

Interventions

Intervention: physiotherapist-supervised moderate exercise (aerobic-treadmill walking and cycling ergometry) programme 1 hour 3 times weekly.

Control: no intervention

Duration: 12 weeks

Cointervention: leucine $10 \mathrm{~g} /$ day orally

\begin{tabular}{ll}
\hline Outcomes & $\begin{array}{l}\text { Mortality, adverse events (serious and non-serious), QoL, exercise capacity, anthropometry, and nutri- } \\
\text { tional status }\end{array}$ \\
\hline Country & Spain \\
\hline Inclusion period & January 2010 to June 2010 \\
\hline Publication status & Full-paper article \\
\hline Notes & Additional information about the design, funding, and outcomes received via email from Dr Soriano.
\end{tabular}

Notes

Additional information about the design, funding, and outcomes received via email from Dr Soriano.

\section{Risk of bias}

\begin{tabular}{|c|c|c|}
\hline Bias & Authors' judgement & Support for judgement \\
\hline $\begin{array}{l}\text { Random sequence genera- } \\
\text { tion (selection bias) }\end{array}$ & Low risk & Computer-generated random numbers \\
\hline $\begin{array}{l}\text { Allocation concealment } \\
\text { (selection bias) }\end{array}$ & Low risk & Serially numbered opaque sealed envelopes \\
\hline $\begin{array}{l}\text { Blinding of participants } \\
\text { and personnel (perfor- } \\
\text { mance bias) } \\
\text { All outcomes }\end{array}$ & High risk & Open trial without blinding of participants or personnel \\
\hline $\begin{array}{l}\text { Blinding of outcome as- } \\
\text { sessment (detection bias) } \\
\text { All outcomes }\end{array}$ & High risk & Open trial. Blinding not reported. \\
\hline $\begin{array}{l}\text { Incomplete outcome data } \\
\text { (attrition bias) } \\
\text { All outcomes }\end{array}$ & High risk & $\begin{array}{l}3 / 20 \text { participants were lost or excluded from the analyses ( } 2 \text { intervention due } \\
\text { to poor compliance; } 1 \text { control withdrew consent). Data were analysed as avail- } \\
\text { able-case data. Baseline values with or without dropouts were stated as simi- } \\
\text { lar. }\end{array}$ \\
\hline $\begin{array}{l}\text { Selective reporting (re- } \\
\text { porting bias) }\end{array}$ & Low risk & $\begin{array}{l}\text { Outcomes listed in the trial registration (in ClinicalTrials.gov) corresponded to } \\
\text { the outcomes listed in the paper. Clinically relevant outcomes were reported. }\end{array}$ \\
\hline For-profit funding & Low risk & Funding from Fundacion MAPFRE, Madrid, Spain \\
\hline Other bias & Low risk & No other biases identified \\
\hline $\begin{array}{l}\text { Overall risk of bias assess- } \\
\text { ment (non-mortality out- } \\
\text { comes) }\end{array}$ & High risk & High risk of bias \\
\hline
\end{tabular}


Román 2014 (Continued)

Overall risk of bias assess- Low risk Low risk of bias ment (mortality)

Román 2016

\begin{tabular}{ll}
\hline Methods & Randomised, outpatient, open, parallel-arm trial \\
\hline Participants & 25 outpatients with cirrhosis were included. Baseline data for 23 participants (intervention 14 ; control \\
9) & Participant characteristics (mean \pm standard deviation or $\%$ ) \\
- Age: intervention $62.0 \pm 12.0$; control $63.1 \pm 11.5$ years \\
- Men: intervention $71 \%$; control $78 \%$ \\
- Model of End-Stage Liver Disease score: intervention $8.2 \pm 2.0$; control $9.1 \pm 2.0$ \\
- Child-Pugh score: intervention $5.4 \pm 1.0$; control $5.4 \pm 1.0$ \\
- Body mass index: intervention $31.5 \pm 8.0$; control $30.3 \pm 7.0 \mathrm{~kg} / \mathrm{m}^{2}$ \\
Aetiology \\
- Alcohol: intervention $86 \%$; control $56 \%$ \\
- Chronic hepatitis B/C: intervention $7 \%$; control $22 \%$ \\
Other: intervention $7 \%$; control $22 \%$
\end{tabular}

Interventions

Intervention: exercise programme consisting of 1-hour sessions (10-minute warm-up, 10-15 minutes increasing to 25-30 minutes on bicycle or treadmill. Resistance training for arms 5-10 minutes. Balance, co-ordination, stretching, and relaxation for 10-15 minutes) 3 days per week under supervision of physiotherapists.

Control: sham intervention consisting of 1-hour supervised relaxation 3 times per week.

Duration: 12 weeks

\begin{tabular}{|c|c|c|}
\hline Outcomes & \multicolumn{2}{|c|}{$\begin{array}{l}\text { Mortality, adverse events (serious and non-serious), exercise capacity, anthropometry, and nutritional } \\
\text { status }\end{array}$} \\
\hline Country & \multicolumn{2}{|l|}{ Spain } \\
\hline Inclusion period & \multicolumn{2}{|c|}{ September 2011 to June 2012} \\
\hline Publication status & \multicolumn{2}{|l|}{ Full-paper article } \\
\hline Notes & \multicolumn{2}{|c|}{ Additional information about the design, funding, and outcomes received via email from Dr Soriano. } \\
\hline \multicolumn{3}{|l|}{ Risk of bias } \\
\hline Bias & Authors' judgement & Support for judgement \\
\hline $\begin{array}{l}\text { Random sequence genera- } \\
\text { tion (selection bias) }\end{array}$ & Low risk & Computer-generated random numbers \\
\hline $\begin{array}{l}\text { Allocation concealment } \\
\text { (selection bias) }\end{array}$ & Low risk & Serially numbered opaque sealed envelopes \\
\hline
\end{tabular}


Román 2016 (Continued)

Blinding of participants High risk Open trial without blinding of participants or personnel
and personnel (perfor-
mance bias)
All outcomes

All outcomes

\begin{tabular}{lll}
\hline Blinding of outcome as- & High risk & Open trial without blinding \\
sessment (detection bias) & &
\end{tabular}

All outcomes

Incomplete outcome data High risk (attrition bias)

All outcomes

\begin{abstract}
1 participant in the intervention group and 1 participant in the control group withdrew consent.
\end{abstract}

4 participants in the control group did not perform cardiopulmonary exercise test at the end of the study. Data were analysed as available-case data. Baseline values with or without dropouts were stated as similar.

\begin{tabular}{|c|c|c|}
\hline $\begin{array}{l}\text { Selective reporting (re- } \\
\text { porting bias) }\end{array}$ & Low risk & $\begin{array}{l}\text { The outcomes listed in the trial registration (in ClinicalTrials.gov) correspond- } \\
\text { ed to the outcomes listed in the paper. Clinically relevant outcomes were re- } \\
\text { ported. }\end{array}$ \\
\hline
\end{tabular}

\begin{tabular}{lll}
\hline For-profit funding & Low risk & $\begin{array}{l}\text { Funding from Fundación MAPFRE (www.fundacionmapfre.org) and Decathlon } \\
\text { Foundation (www.fondationdecathlon.com) }\end{array}$ \\
\hline Other bias & Low risk & No other biases identified \\
\hline $\begin{array}{l}\text { Overall risk of bias assess- } \\
\text { ment (non-mortality out- } \\
\text { comes) }\end{array}$ & High risk & High risk of bias \\
\hline $\begin{array}{l}\text { Overall risk of bias assess- } \\
\text { ment (mortality) }\end{array}$ & Low risk & Low risk of bias \\
\hline
\end{tabular}

Zenith 2014

\begin{tabular}{ll}
\hline Methods & Randomised, outpatient, open, parallel-arm trial \\
\hline Participants & 20 participants with cirrhosis. Baseline data for 19 participants (intervention 9; control 10) \\
& Participant characteristics (mean \pm standard deviation or $\%)$ \\
& - Age: intervention $56.4 \pm 7.7$; control $58.6 \pm 5.8$ years \\
- Men: intervention $78 \%$; control $80 \%$ \\
- Child-Pugh score: intervention $6.2 \pm 1.4$; control $6.3 \pm 1.4$ \\
- Model of End-Stage Liver Disease score: intervention $9.7 \pm 2.4$; control $10.2 \pm 1.0$ \\
- Body mass index: intervention $27.7 \pm 3.8$; control $28.9 \pm 4.2 \mathrm{~kg} / \mathrm{m}^{2}$ \\
Aetiology \\
- Alcohol: intervention $33.3 \%$; control $30 \%$ \\
- Hepatitis B/C: intervention $11.1 \% / 11.1 \%$; control $10 \% / 30 \%$. \\
- NASH: intervention $0 \%$; control $0 \%$
\end{tabular}

Interventions

Intervention: supervised aerobic (ergometer cycle) training 3 times per week for 8 weeks (30-minute sessions increasing with 2.5 minutes per session each week).

Control: no intervention 
Zenith 2014 (Continued)

Duration: 8 weeks

Outcomes Mortality, adverse events (serious and non-serious), QoL, exercise capacity, anthropometry, and nutritional status

\begin{tabular}{ll}
\hline Country & Canada \\
\hline Inclusion period & February 2013 to June 2013 \\
\hline Publication status & Full paper article \\
\hline Notes &
\end{tabular}

\section{Risk of bias}

\begin{tabular}{|c|c|c|}
\hline Bias & Authors' judgement & Support for judgement \\
\hline $\begin{array}{l}\text { Random sequence genera- } \\
\text { tion (selection bias) }\end{array}$ & Low risk & Computer-generated random numbers \\
\hline $\begin{array}{l}\text { Allocation concealment } \\
\text { (selection bias) }\end{array}$ & Low risk & Serially numbered opaque sealed envelopes \\
\hline $\begin{array}{l}\text { Blinding of participants } \\
\text { and personnel (perfor- } \\
\text { mance bias) } \\
\text { All outcomes }\end{array}$ & High risk & Open trial without blinding of participants or personnel \\
\hline $\begin{array}{l}\text { Blinding of outcome as- } \\
\text { sessment (detection bias) } \\
\text { All outcomes }\end{array}$ & High risk & $\begin{array}{l}\text { Open trial without blinded outcome assessment (the assessor measuring the } \\
\text { second thigh circumference and ultrasound thickness was blinded to the prior } \\
\text { measurements). }\end{array}$ \\
\hline $\begin{array}{l}\text { Incomplete outcome data } \\
\text { (attrition bias) } \\
\text { All outcomes }\end{array}$ & Low risk & $\begin{array}{l}1 \text { participant was excluded before initiating exercise, but after randomisation } \\
\text { due to exclusion criteria (Child-Pugh C disease). The remaining participants } \\
\text { were all included in the analyses. }\end{array}$ \\
\hline $\begin{array}{l}\text { Selective reporting (re- } \\
\text { porting bias) }\end{array}$ & Low risk & $\begin{array}{l}\text { The outcomes in the trial protocol and trial publication were the same. The in- } \\
\text { vestigators registered the trial before inclusion of the first participant. Clinical- } \\
\text { ly relevant outcomes were reported. }\end{array}$ \\
\hline For-profit funding & Low risk & $\begin{array}{l}\text { Funding from the University of Alberta Hospital Foundation and Canadian Liv- } \\
\text { er Foundation Graduate Studentship Award }\end{array}$ \\
\hline Other bias & Low risk & No other biases identified \\
\hline $\begin{array}{l}\text { Overall risk of bias assess- } \\
\text { ment (non-mortality out- } \\
\text { comes) }\end{array}$ & High risk & High risk of bias \\
\hline $\begin{array}{l}\text { Overall risk of bias assess- } \\
\text { ment (mortality) }\end{array}$ & Low risk & Low risk of bias \\
\hline
\end{tabular}

6MWT: Six-Minute Walk Test; HVPG: hepatic venous pressure gradient; NASH: non-alcoholic steatohepatitis; QoL: quality of life.

Characteristics of excluded studies [ordered by study ID] 


\begin{tabular}{ll}
\hline Study & Reason for exclusion \\
\hline Berzigotti 2016a & $\begin{array}{l}\text { Prospective observational study including } 60 \text { participants with compensated cirrhosis, portal hy- } \\
\text { pertension, and } \mathrm{BMI}>26 \mathrm{~kg} / \mathrm{m}^{2} \text { allocated to an intensive } 16 \text {-week lifestyle intervention (diet and } \\
\text { exercise) programme. No control group. }\end{array}$
\end{tabular}

Campillo 1990b

Prospective observational study examining aerobic capacity in a subgroup of 4 participants with cirrhosis allocated to a 4- to 5-week physical programme consisting of 45-60 minutes on a bicycle or treadmill 5 times per week. The total number of participants included was 24 . No control group.

Debette-Gratien 2014

Prospective observational study evaluating the acceptability of a 12-week personalised programme of adapted physical activity and its impact on aerobic capacity, muscle strength, and quality of life before liver transplantation. No control group.

Degoricija 2003

Randomised clinical trial evaluating the clinical and neurohumoral response to paracentesis, volume expansion, diuretics, and bedrest in 50 participants with cirrhosis and tense ascites. The trial did not evaluate physical exercise.

Hiraoka 2017 Prospective observational study with 33 participants with cirrhosis, 30 with Child-Pugh A.

Prior to the intervention the mean number of daily steps were calculated using a pedometer for 23 weeks. A late evening snack of BCAA supplementation (protein $13.5 \mathrm{~g}, 210 \mathrm{kcal} /$ day) and walking exercise (additional 2000 steps per day prescribed) were started. Outcomes were measured 1, 2, and 3 months after starting the intervention. No control group.

Konishi 2011

Prospective observational study with 17 participants with chronic hepatitis $\mathrm{C}$, 3 with cirrhosis Child-Pugh A. Dietary intervention lasting 8 months $(1.2-1.5 \mathrm{~g} / \mathrm{kg}$ of protein and adjusted calorie intake). 2 months after inclusion, the participants were followed by pedometer-guided intervention of at least 8000 steps per day for the remaining 6 months. No control group.

Nishida 2016 Prospective observational study including 9 participants with compensated liver cirrhosis received oral BCAA and bench step exercises. No control group.

Pattullo 2013

Prospective observational study including 16 obese $\left(\mathrm{BMI}>30 \mathrm{~kg} / \mathrm{m}^{2}\right)$ participants with chronic hepatis C. 6 participants had cirrhosis. Intervention consisted of a 24-week lifestyle intervention with nutritional advise and more than 10,000 steps per day (monitored by pedometer). No control group.

Ritland 1983

Prospective observational study including 9 participants with chronic active hepatitis $(5$ with cirrhosis) allocated to a home-based exercise programme of 30 minutes 3 times per week. Peak oxygen uptake was evaluated at 4-6 weeks and 10-12 weeks. No control group.

BCAA: branched chain amino acids; BMI: body mass index

DATA AND ANALYSES

Comparison 1. Exercise versus control

\begin{tabular}{lllll}
\hline Outcome or subgroup title & No. of studies & $\begin{array}{l}\text { No. of partici- } \\
\text { pants }\end{array}$ & Statistical method & Effect size \\
\hline 1 All-cause mortality & 6 & 173 & $\begin{array}{l}\text { Risk Ratio (M-H, Random, 95\% } \\
\text { Cl) }\end{array}$ & $0.19[0.01,3.73]$ \\
\hline
\end{tabular}




\begin{tabular}{|c|c|c|c|c|}
\hline Outcome or subgroup title & No. of studies & $\begin{array}{l}\text { No. of partici- } \\
\text { pants }\end{array}$ & Statistical method & Effect size \\
\hline 2 Serious adverse events & 6 & 173 & $\begin{array}{l}\text { Risk Ratio (M-H, Random, 95\% } \\
\mathrm{Cl} \text { ) }\end{array}$ & $0.61[0.19,1.94]$ \\
\hline 3 Health-related quality of life & 5 & & $\begin{array}{l}\text { Mean Difference (IV, Random, } \\
95 \% \mathrm{CI} \text { ) }\end{array}$ & Subtotals only \\
\hline $\begin{array}{l}\text { 3.1 Chronic Liver Disease Question- } \\
\text { naire (total score) }\end{array}$ & 3 & 81 & $\begin{array}{l}\text { Mean Difference (IV, Random, } \\
95 \% \mathrm{CI} \text { ) }\end{array}$ & $0.11[-0.44,0.67]$ \\
\hline $\begin{array}{l}\text { 3.2 EuroQol-Visual Analogue Scale } \\
\text { (total score) }\end{array}$ & 2 & 56 & $\begin{array}{l}\text { Mean Difference (IV, Random, } \\
95 \% \mathrm{CI} \text { ) }\end{array}$ & $3.11[-24.03,30.24]$ \\
\hline $\begin{array}{l}\text { 3.3 36-item Short Form (Mental } \\
\text { Component Summary) }\end{array}$ & 2 & 51 & $\begin{array}{l}\text { Mean Difference (IV, Random, } \\
95 \% \mathrm{CI} \text { ) }\end{array}$ & $2.26[-3.84,8.37]$ \\
\hline 4 Non-serious adverse events & 6 & 173 & $\begin{array}{l}\text { Risk Ratio (M-H, Random, 95\% } \\
\mathrm{Cl} \text { ) }\end{array}$ & $1.97[0.53,7.33]$ \\
\hline $\begin{array}{l}5 \text { Anthropometric measurements: } \\
\text { lean body mass }(\mathrm{kg})\end{array}$ & 4 & & $\begin{array}{l}\text { Mean Difference (IV, Random, } \\
95 \% \mathrm{Cl} \text { ) }\end{array}$ & Subtotals only \\
\hline $\begin{array}{l}\text { 5.1 Dual-energy } x \text {-ray absorptiome- } \\
\text { try (DXA) - lean leg mass (kg) }\end{array}$ & 1 & 22 & $\begin{array}{l}\text { Mean Difference (IV, Random, } \\
95 \% \mathrm{Cl} \text { ) }\end{array}$ & $0.46[-2.92,3.84]$ \\
\hline $\begin{array}{l}5.2 \text { Ultrasound - mean compression } \\
\text { index }\left(\mathrm{cm} / \mathrm{m}^{2}\right)\end{array}$ & 2 & 56 & $\begin{array}{l}\text { Mean Difference (IV, Random, } \\
95 \% \mathrm{CI} \text { ) }\end{array}$ & $0.07[-0.03,0.17]$ \\
\hline 5.3 Bioimpedance - dry lean (kg) & 1 & 34 & $\begin{array}{l}\text { Mean Difference (IV, Random, } \\
95 \% \mathrm{CI} \text { ) }\end{array}$ & $2.30[-0.73,5.33]$ \\
\hline $\begin{array}{l}6 \text { Anthropometric measurements: } \\
\text { mid-arm circumference }(\mathrm{cm})\end{array}$ & 3 & 72 & $\begin{array}{l}\text { Mean Difference (IV, Random, } \\
95 \% \mathrm{Cl})\end{array}$ & $2.61[0.36,4.85]$ \\
\hline $\begin{array}{l}7 \text { Anthropometric measurements: } \\
\text { thigh circumference }(\mathrm{cm})\end{array}$ & 5 & 128 & $\begin{array}{l}\text { Mean Difference (IV, Random, } \\
95 \% \mathrm{CI} \text { ) }\end{array}$ & $1.76[-0.26,3.77]$ \\
\hline $\begin{array}{l}8 \text { Anthropometric measurements: } \\
\text { body mass index }\left(\mathrm{kg} / \mathrm{m}^{2}\right)\end{array}$ & 6 & 154 & $\begin{array}{l}\text { Mean Difference (IV, Random, } \\
95 \% \mathrm{CI} \text { ) }\end{array}$ & $0.97[-0.48,2.42]$ \\
\hline $\begin{array}{l}9 \text { Physical fitness: peak oxygen up- } \\
\text { take }(\mathrm{mL} / \mathrm{kg} / \text { minute })\end{array}$ & 4 & 100 & $\begin{array}{l}\text { Mean Difference (IV, Random, } \\
95 \% \mathrm{Cl})\end{array}$ & $0.30[-2.74,3.35]$ \\
\hline $\begin{array}{l}10 \text { Physical fitness: 6-Minute Walk } \\
\text { Test ( } \mathrm{m} \text { in total) }\end{array}$ & 4 & 105 & $\begin{array}{l}\text { Mean Difference (IV, Random, } \\
95 \% \mathrm{CI})\end{array}$ & $\begin{array}{l}56.06[-9.14 \\
121.26]\end{array}$ \\
\hline 11 Blood glucose (mmol/L) & 2 & 59 & $\begin{array}{l}\text { Mean Difference (IV, Random, } \\
95 \% \mathrm{Cl} \text { ) }\end{array}$ & $0.27[-0.54,1.08]$ \\
\hline 12 Serum albumin $(\mathrm{g} / \mathrm{L})$ & 6 & 155 & $\begin{array}{l}\text { Mean Difference (IV, Random, } \\
95 \% \mathrm{Cl} \text { ) }\end{array}$ & $0.05[-1.48,1.59]$ \\
\hline 13 Serum creatinine $(\mu \mathrm{mol} / \mathrm{L})$ & 4 & 99 & $\begin{array}{l}\text { Mean Difference (IV, Random, } \\
95 \% \mathrm{Cl})\end{array}$ & $-1.54[-8.03,4.95]$ \\
\hline
\end{tabular}




\begin{tabular}{lllll}
\hline Outcome or subgroup title & No. of studies & $\begin{array}{l}\text { No. of partici- } \\
\text { pants }\end{array}$ & Statistical method & Effect size \\
\hline $14 \mathrm{Ammonia}(\mu \mathrm{mol} / \mathrm{L})$ & 3 & 73 & $\begin{array}{l}\text { Mean Difference (IV, Random, } \\
95 \% \mathrm{Cl})\end{array}$ & $8.39[-4.20,20.97]$ \\
\hline
\end{tabular}

Analysis 1.1. Comparison 1 Exercise versus control, Outcome 1 All-cause mortality.

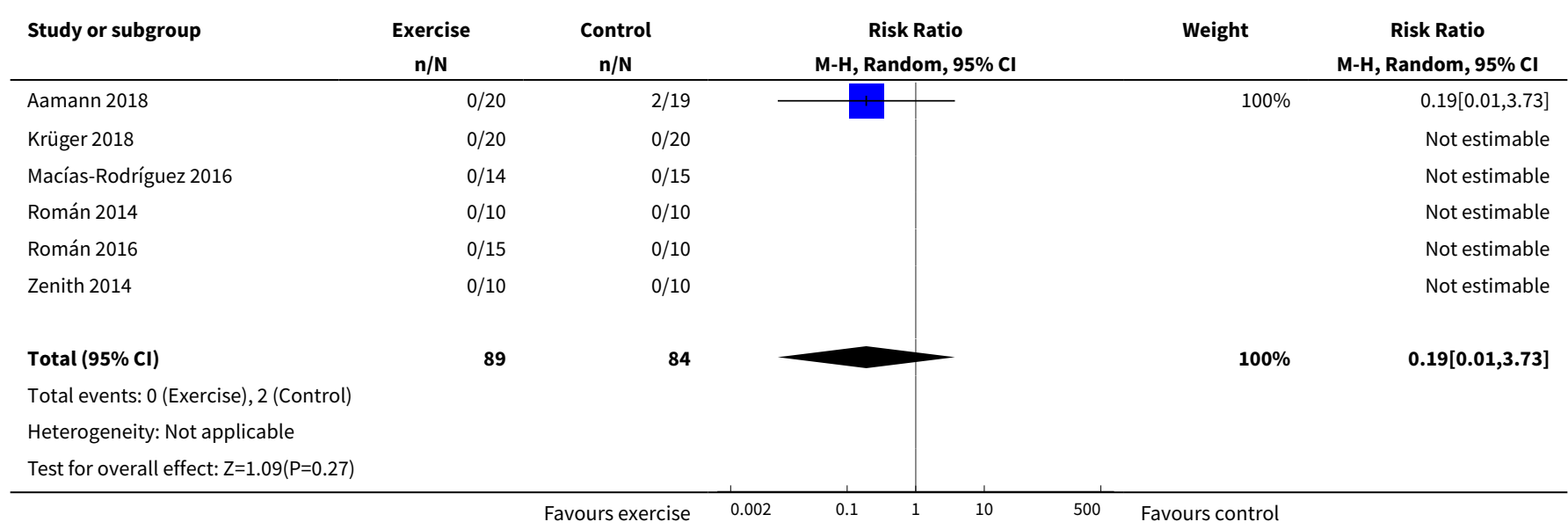

Analysis 1.2. Comparison 1 Exercise versus control, Outcome 2 Serious adverse events.

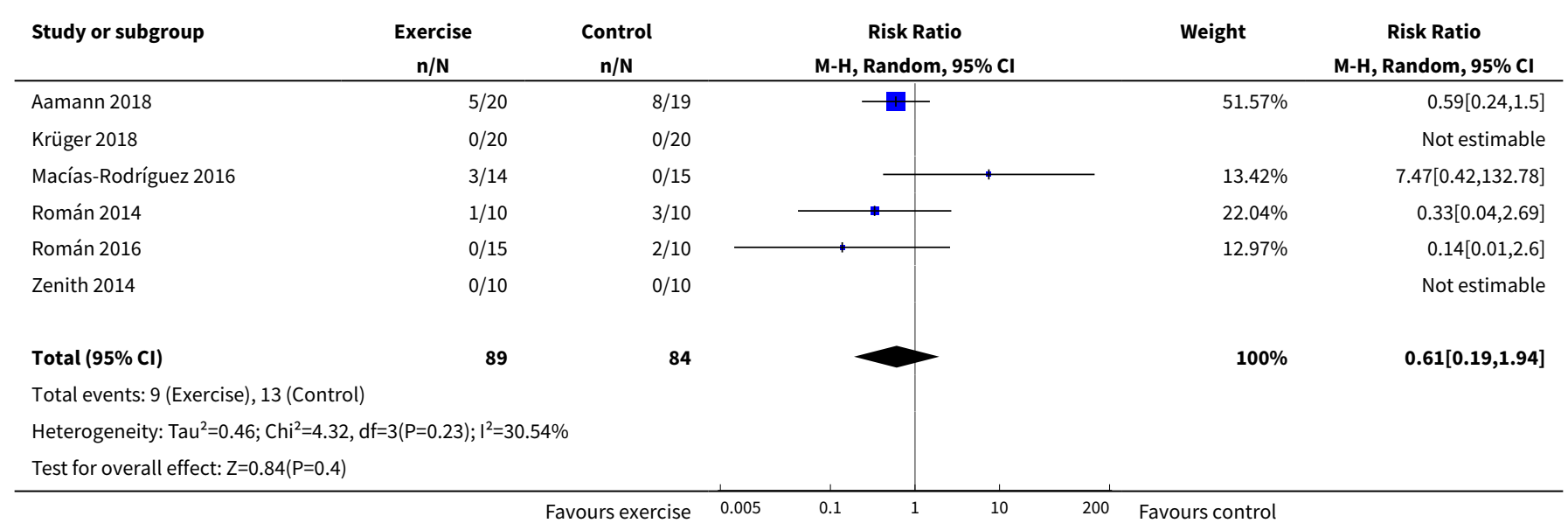

Analysis 1.3. Comparison 1 Exercise versus control, Outcome 3 Health-related quality of life.

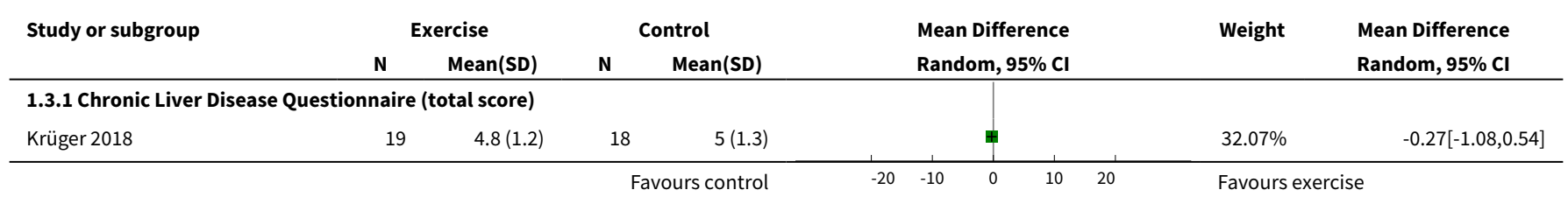




\begin{tabular}{|c|c|c|c|c|c|c|c|}
\hline \multirow[t]{2}{*}{ Study or subgroup } & \multicolumn{2}{|c|}{ Exercise } & \multicolumn{2}{|c|}{ Control } & \multirow{2}{*}{$\begin{array}{l}\text { Mean Difference } \\
\text { Random, } 95 \% \mathrm{Cl}\end{array}$} & \multirow[t]{2}{*}{ Weight } & \multirow{2}{*}{$\begin{array}{l}\text { Mean Difference } \\
\text { Random, } 95 \% \mathrm{Cl}\end{array}$} \\
\hline & $\mathbf{N}$ & $\operatorname{Mean}(S D)$ & $\mathbf{N}$ & Mean(SD) & & & \\
\hline Macías-Rodríguez 2016 & 13 & $5.3(1.2)$ & 12 & $5.4(0.9)$ & 申 & $30.96 \%$ & $-0.1[-0.93,0.73]$ \\
\hline Zenith 2014 & 9 & $6(0.6)$ & 10 & $5.4(1)$ & $\Phi$ & $36.97 \%$ & $0.62[-0.1,1.34]$ \\
\hline Subtotal $\star \star \star$ & 41 & & 40 & & 1 & $100 \%$ & $0.11[-0.44,0.67]$ \\
\hline \multicolumn{8}{|c|}{ Heterogeneity: $\operatorname{Tau}^{2}=0.08 ; \mathrm{Chi}^{2}=3, \mathrm{df}=2(\mathrm{P}=0.22) ; \mathrm{I}^{2}=33.41 \%$} \\
\hline \multicolumn{8}{|c|}{ Test for overall effect: $\mathrm{Z}=0.39(\mathrm{P}=0.69)$} \\
\hline \multicolumn{8}{|c|}{ 1.3.2 EuroQol-Visual Analogue Scale (total score) } \\
\hline Krüger 2018 & 19 & $62.6(16.4)$ & 18 & $72.9(18.5)$ & 1 & $51.6 \%$ & $-10.3[-21.59,0.99]$ \\
\hline Zenith 2014 & 9 & $83.6(11.1)$ & 10 & $66.2(21)$ & + & $48.4 \%$ & $17.4[2.5,32.3]$ \\
\hline Subtotal $* \star \star$ & 28 & & 28 & & & $100 \%$ & $3.11[-24.03,30.24]$ \\
\hline \multicolumn{8}{|c|}{ Heterogeneity: $\mathrm{Tau}^{2}=338.17 ; \mathrm{Chi}^{2}=8.44, \mathrm{df}=1(\mathrm{P}=0) ; \mathrm{I}^{2}=88.15 \%$} \\
\hline \multicolumn{8}{|c|}{ 1.3.3 36-item Short Form (Mental Component Summary) } \\
\hline Aamann 2018 & 19 & $54(8.5)$ & 15 & $52.2(11.1)$ & & $80.78 \%$ & $1.8[-4.99,8.59]$ \\
\hline Román 2014 & 8 & $51.1(4.8)$ & 9 & $46.9(20.7)$ & $*$ & $19.22 \%$ & $4.2[-9.73,18.13]$ \\
\hline Subtotal $\star \star \star$ & 27 & & 24 & & & $100 \%$ & $2.26[-3.84,8.37]$ \\
\hline \multicolumn{8}{|c|}{ Heterogeneity: $\operatorname{Tau}^{2}=0 ; \mathrm{Chi}^{2}=0.09, \mathrm{df}=1(\mathrm{P}=0.76) ;\left.\right|^{2}=0 \%$} \\
\hline \multicolumn{8}{|c|}{ Test for overall effect: $Z=0.73(P=0.47)$} \\
\hline Test for subgroup differe & $52, \mathrm{df}=$ & $P=0.77), I^{2}=0 \%$ & & & & & \\
\hline
\end{tabular}

\section{Analysis 1.4. Comparison 1 Exercise versus control, Outcome 4 Non-serious adverse events.}

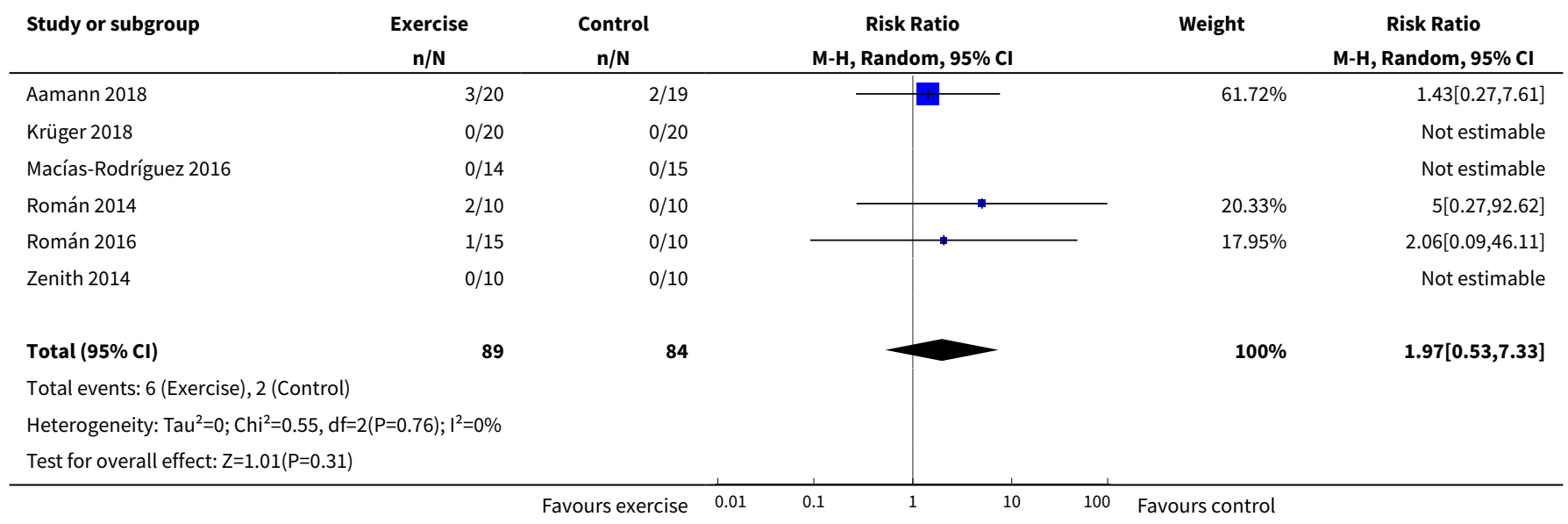

\section{Analysis 1.5. Comparison 1 Exercise versus control, Outcome}

5 Anthropometric measurements: lean body mass $(\mathrm{kg})$.

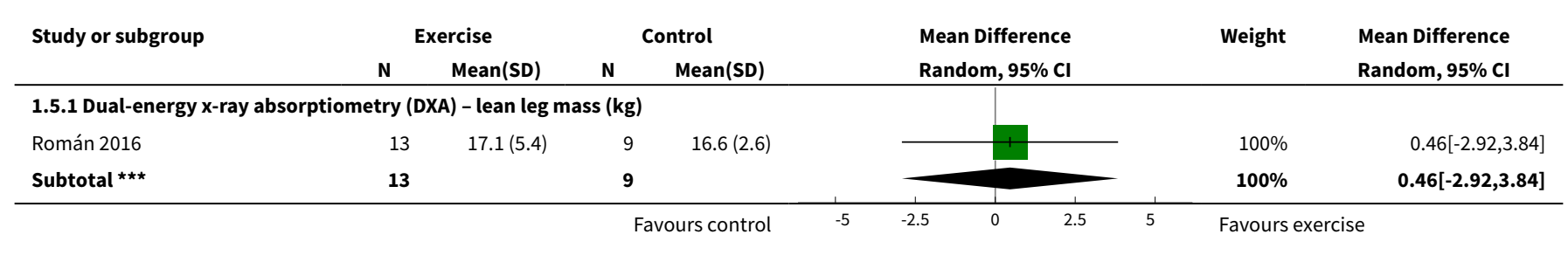




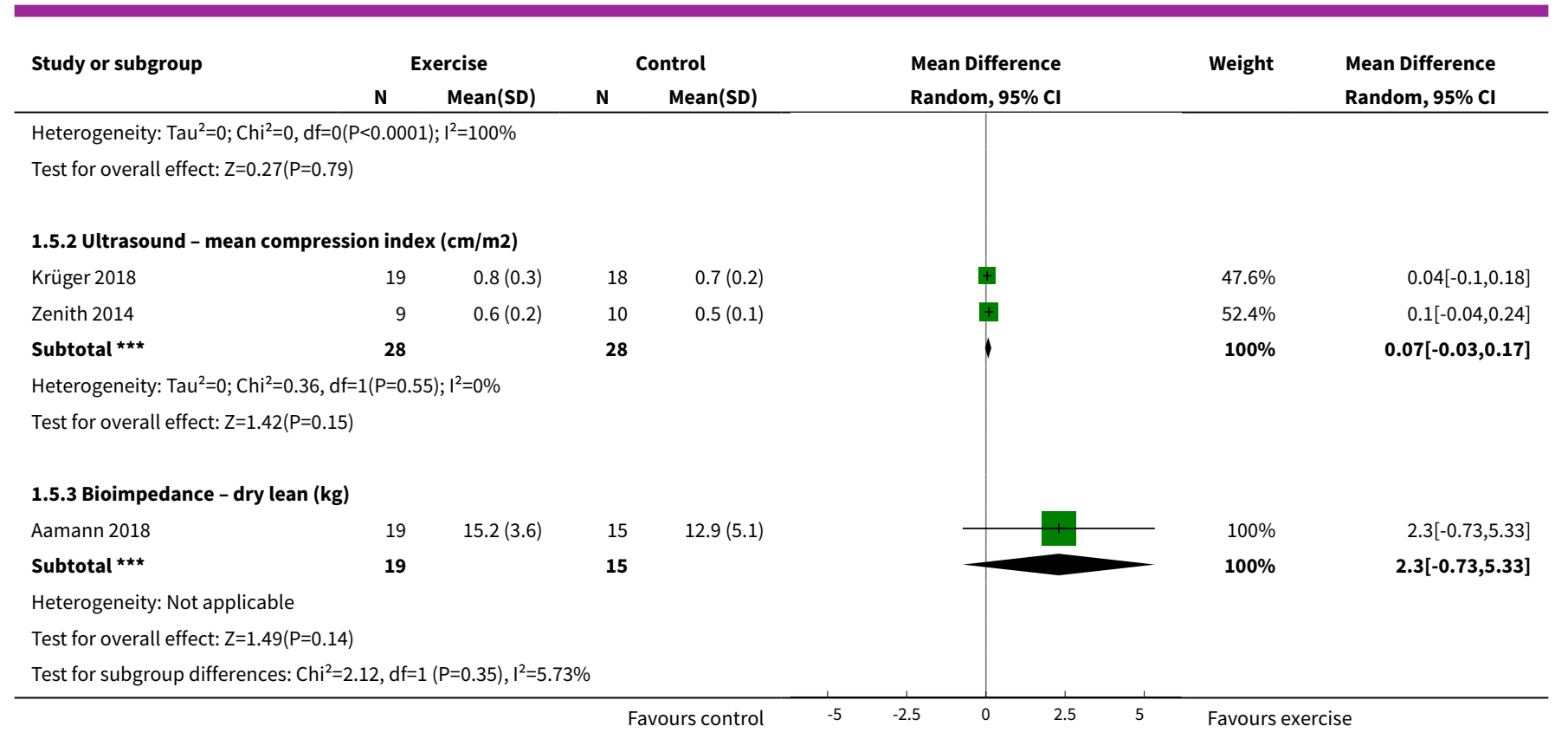

Analysis 1.6. Comparison 1 Exercise versus control, Outcome 6 Anthropometric measurements: mid-arm circumference $(\mathrm{cm})$.

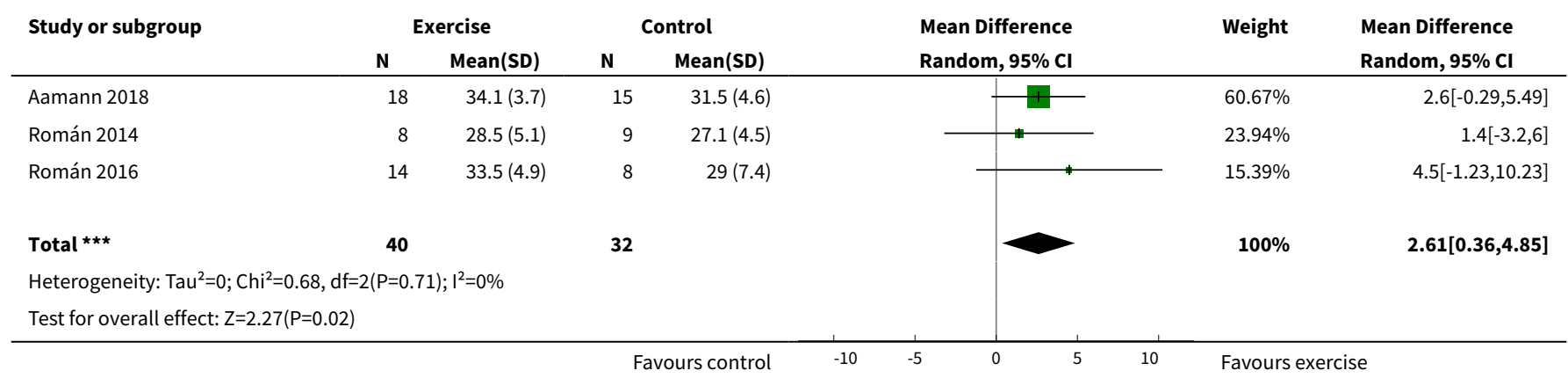

Analysis 1.7. Comparison 1 Exercise versus control, Outcome 7 Anthropometric measurements: thigh circumference $(\mathrm{cm})$.

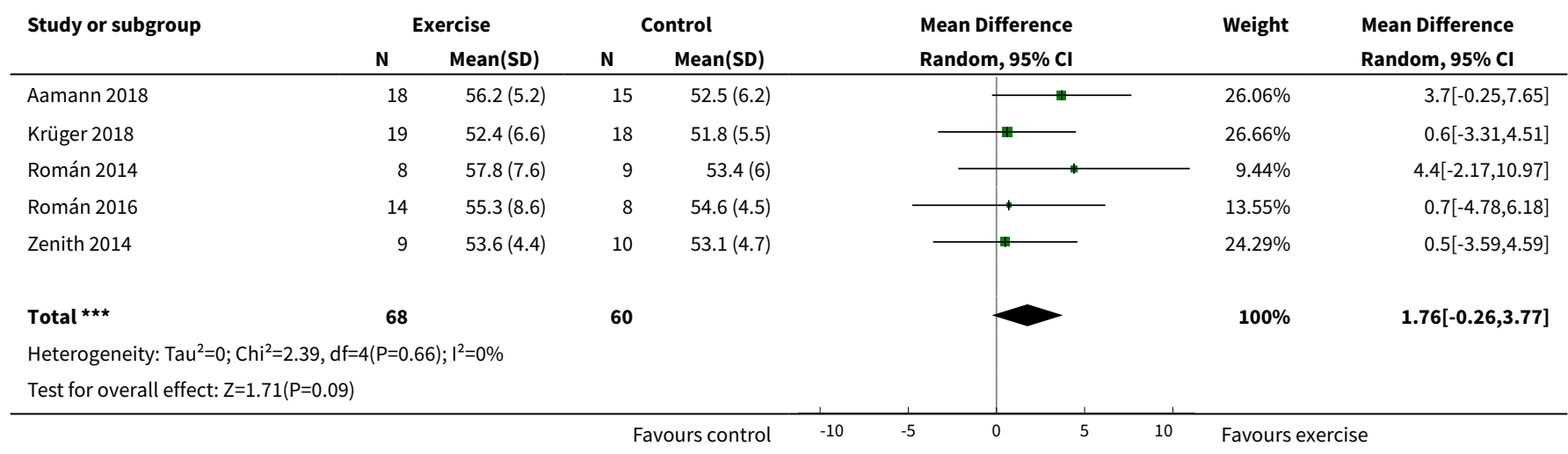




\section{Analysis 1.8. Comparison 1 Exercise versus control, Outcome}

\section{Anthropometric measurements: body mass index $\left(\mathrm{kg} / \mathrm{m}^{2}\right)$.}

\begin{tabular}{|c|c|c|c|c|c|c|c|}
\hline \multirow[t]{2}{*}{ Study or subgroup } & \multicolumn{2}{|c|}{ Exercise } & \multicolumn{2}{|c|}{ Control } & \multirow{2}{*}{$\begin{array}{l}\text { Mean Difference } \\
\text { Random, } 95 \% \mathrm{Cl}\end{array}$} & \multirow[t]{2}{*}{ Weight } & \multirow{2}{*}{$\begin{array}{l}\text { Mean Difference } \\
\text { Random, } 95 \% \mathrm{Cl}\end{array}$} \\
\hline & $\mathbf{N}$ & $\operatorname{Mean}(S D)$ & $\mathbf{N}$ & $\operatorname{Mean}(S D)$ & & & \\
\hline Aamann 2018 & 19 & $27.9(3.3)$ & 15 & $25.5(4.1)$ & II & $32.41 \%$ & $2.4[-0.15,4.95]$ \\
\hline Krüger 2018 & 19 & $29.3(5.1)$ & 18 & $29.2(5)$ & & $19.91 \%$ & $0.1[-3.15,3.35]$ \\
\hline Macías-Rodríguez 2016 & 13 & $27.6(5.8)$ & 12 & $27(2.2)$ & $T^{2}$ & $18.36 \%$ & $0.6[-2.79,3.99]$ \\
\hline Román 2014 & 8 & $28(5.7)$ & 9 & $27.9(4.5)$ & & $8.78 \%$ & $0.1[-4.8,5]$ \\
\hline Román 2016 & 14 & $31.5(6.6)$ & 8 & $30(4)$ & & $10.74 \%$ & $1.5[-2.93,5.93]$ \\
\hline Total $\star \star \star$ & 82 & & 72 & & & $100 \%$ & $0.97[-0.48,2.42]$ \\
\hline \multicolumn{8}{|c|}{ Heterogeneity: $\mathrm{Tau}^{2}=0 ; \mathrm{Chi}^{2}=2.47, \mathrm{df}=5(\mathrm{P}=0.78) ; \mathrm{I}^{2}=0 \%$} \\
\hline \multicolumn{3}{|c|}{ Test for overall effect: $Z=1.31(P=0.19)$} & & & & & \\
\hline
\end{tabular}

\section{Analysis 1.9. Comparison 1 Exercise versus control, Outcome} 9 Physical fitness: peak oxygen uptake (mL/kg/minute).

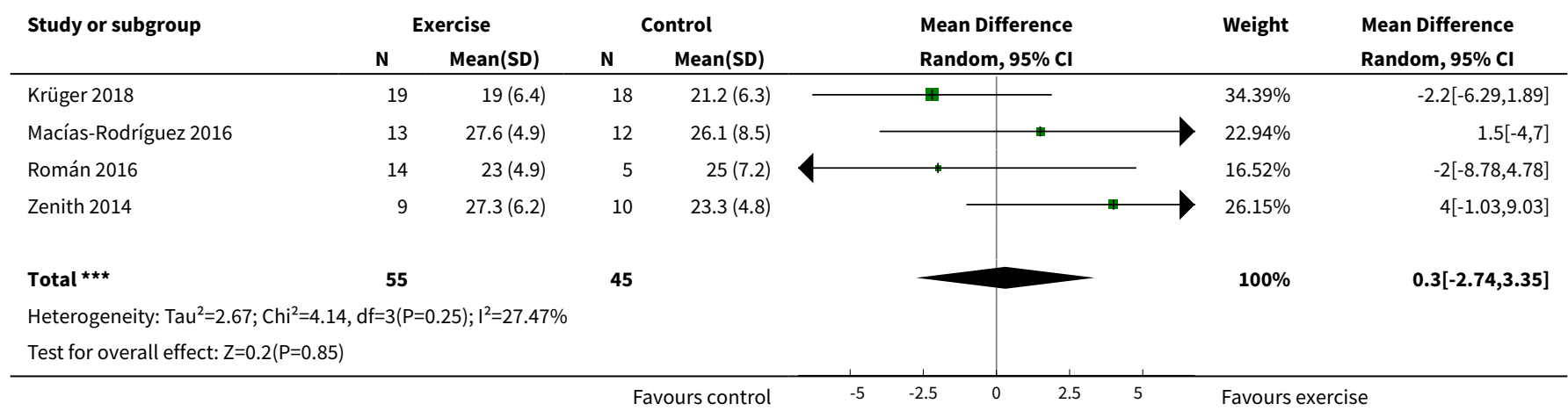

Analysis 1.10. Comparison 1 Exercise versus control, Outcome 10 Physical fitness: 6-Minute Walk Test ( $m$ in total).

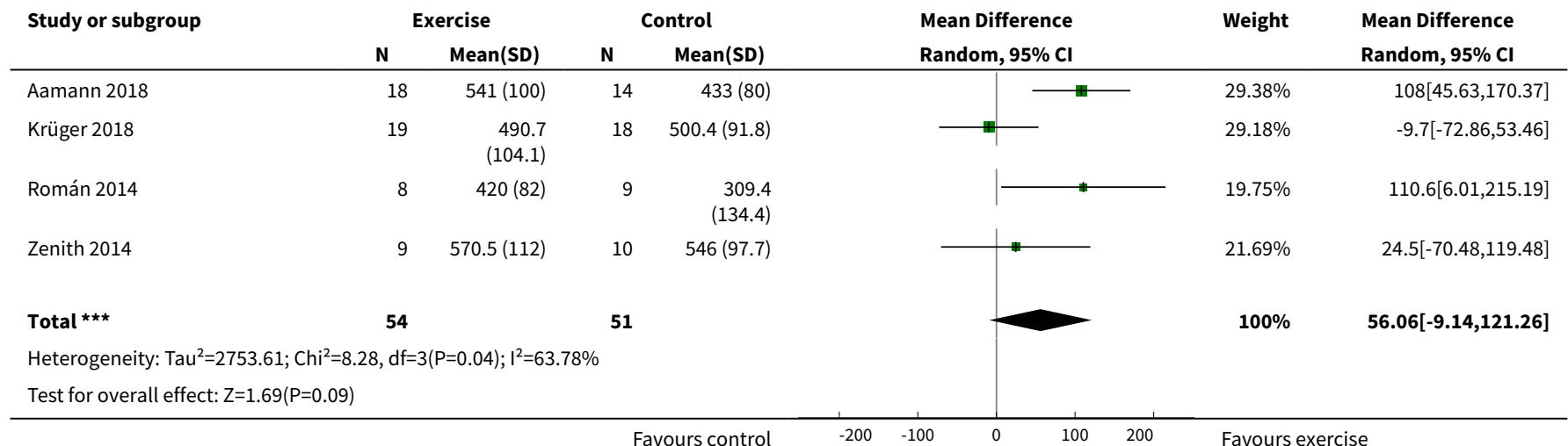


Analysis 1.11. Comparison 1 Exercise versus control, Outcome 11 Blood glucose (mmol/L).

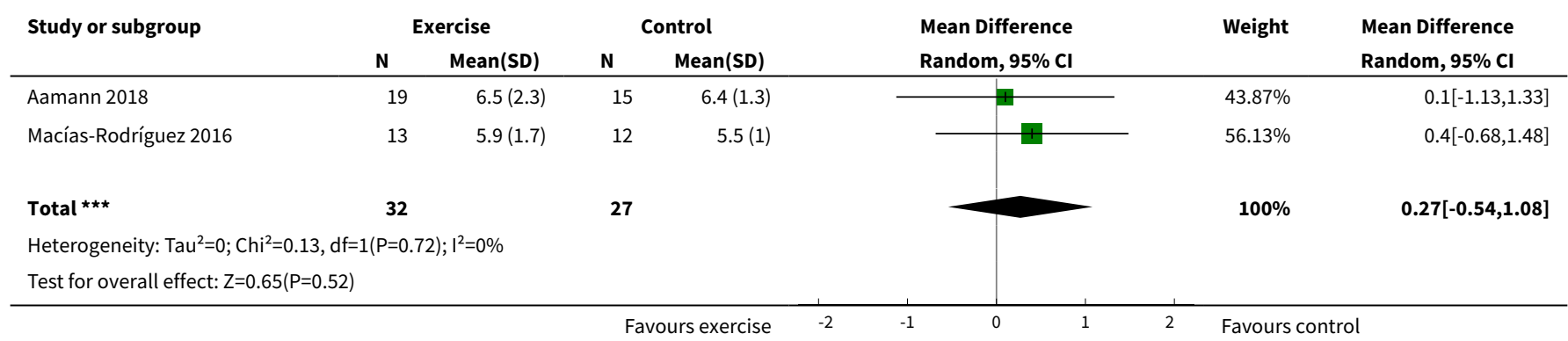

Analysis 1.12. Comparison 1 Exercise versus control, Outcome 12 Serum albumin (g/L).

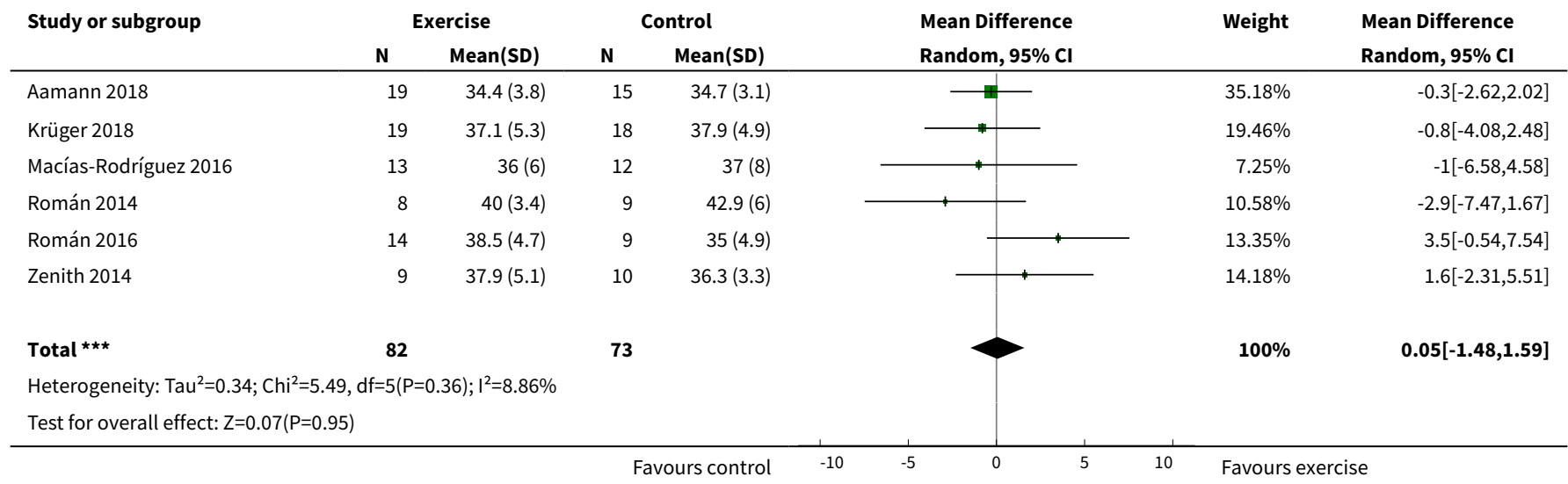

Analysis 1.13. Comparison 1 Exercise versus control, Outcome 13 Serum creatinine ( $\mu \mathrm{mol} / \mathrm{L}$ ).

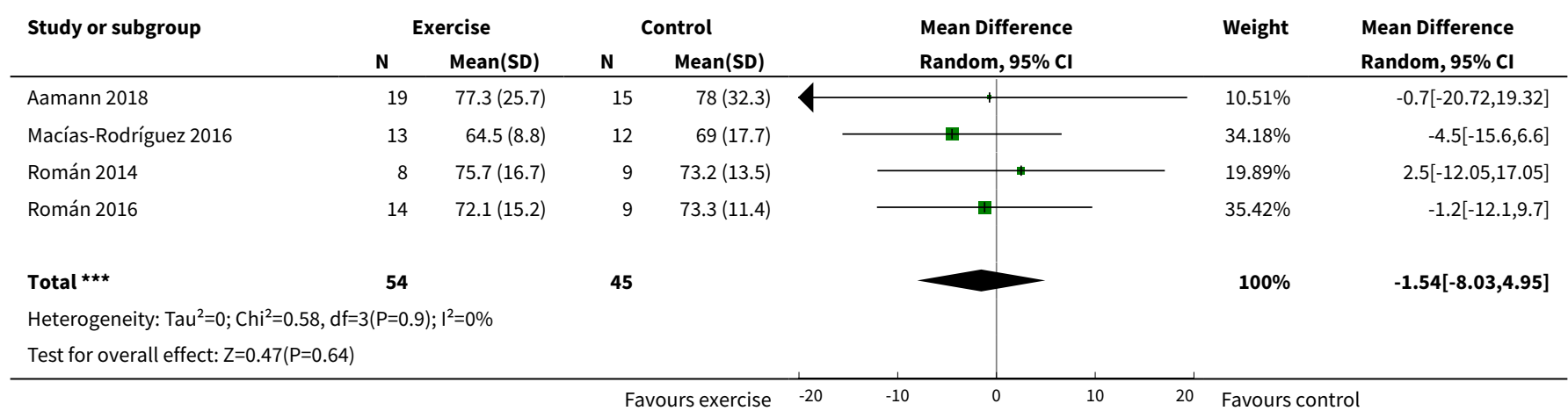


Analysis 1.14. Comparison 1 Exercise versus control, Outcome 14 Ammonia ( $\mu \mathrm{mol} / \mathrm{L})$.

\begin{tabular}{|c|c|c|c|c|c|c|c|}
\hline \multirow[t]{2}{*}{ Study or subgroup } & \multicolumn{2}{|c|}{ Exercise } & \multicolumn{2}{|c|}{ Control } & \multirow{2}{*}{$\begin{array}{l}\text { Mean Difference } \\
\text { Random, 95\% Cl }\end{array}$} & \multirow[t]{2}{*}{ Weight } & \multirow{2}{*}{$\begin{array}{l}\text { Mean Difference } \\
\text { Random, } 95 \% \mathrm{CI}\end{array}$} \\
\hline & $\mathbf{N}$ & Mean(SD) & $\mathbf{N}$ & Mean(SD) & & & \\
\hline Aamann 2018 & 18 & $46.8(21.2)$ & 15 & $38.3(22.3)$ & $\longrightarrow$ & $70.91 \%$ & $8.5[-6.44,23.44]$ \\
\hline Macías-Rodríguez 2016 & 12 & $82.8(49.3)$ & 11 & $73.5(34.3)$ & 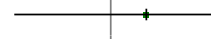 & $13.32 \%$ & $9.3[-25.18,43.78]$ \\
\hline Román 2014 & 8 & $64.2(30.3)$ & 9 & $57.1(36.3)$ & $T$ & $15.78 \%$ & $7.1[-24.57,38.77]$ \\
\hline 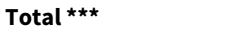 & 38 & & 35 & & & $100 \%$ & $8.39[-4.2,20.97]$ \\
\hline \multicolumn{3}{|c|}{ Test for overall effect: $Z=1.31(P=0.19)$} & & & & & \\
\hline
\end{tabular}

ADDITIONAL TABLES

Table 1. Serious adverse events

\begin{tabular}{|c|c|c|c|}
\hline Trial & $\begin{array}{l}\text { Number of partici- } \\
\text { pants }\end{array}$ & Intervention group & Control group \\
\hline Aamann 2018 & 37 & $\begin{array}{l}5 \text { participants: } \\
\text { - ascites requiring paracentesis ( } 2 \text { ) } \\
\text { - commotio (1) } \\
\text { - prostate cancer (1) } \\
\text { - inflammatory bowel disease re- } \\
\text { quiring colectomy (1) }\end{array}$ & $\begin{array}{l}8 \text { participants: } \\
\text { - pneumonia (1) } \\
\text { - stroke (1) } \\
\text { - fractured foot (1) } \\
\text { - broken osteosynthesis (1) } \\
\text { - spontaneous bacterial peritonitis with septic } \\
\text { - } \text { shock (1) } \\
\text { - } \text { acuer of unknown origin (1) } \\
\text { achronic liver failure (2) }\end{array}$ \\
\hline
\end{tabular}

\begin{tabular}{llll}
\hline Krüger 2018 & 37 & None & None \\
\hline Macías-Rodríguez & 26 & 3 participants: & None \\
2016 & & bleeding NSAID-induced duode- \\
& & nal ulcer (1) \\
& & perianal abscess (1) \\
& & severe hypertension (1) & \\
& &
\end{tabular}

\begin{tabular}{|c|c|c|c|}
\hline Román 2014 & 20 & $\begin{array}{l}1 \text { participant: } \\
\text { - hepatocellular carcinoma (1) }\end{array}$ & $\begin{array}{l}3 \text { participants: } \\
\text { - variceal bleeding (1) } \\
\text { - septic shock due to urinary tract infection (1) } \\
\text { - fever of unknown origin (1) }\end{array}$ \\
\hline Román 2016 & 25 & None & $\begin{array}{l}2 \text { participants: } \\
\text { - hepatocellular carcinoma (1) } \\
\text { - breast cancer (adenocarcinoma) (1) }\end{array}$ \\
\hline Zenith 2014 & 19 & None & None \\
\hline
\end{tabular}

NSAID: non-steroidal anti-inflammatory drug 


\section{AP PEN DICES}

\section{Appendix 1. Search strategies}

\begin{tabular}{|c|c|c|}
\hline Database & Time span & Search strategy \\
\hline $\begin{array}{l}\text { Cochrane Hepato-Bil- } \\
\text { iary Group Controlled } \\
\text { Trials Register }\end{array}$ & February 2018 & $\begin{array}{l}\text { (exercise* or physical activit }{ }^{\star} \text { or training or (oxygen and (uptake or consump- } \\
\text { tion))) AND cirrho* }\end{array}$ \\
\hline $\begin{array}{l}\text { Cochrane Central Reg- } \\
\text { ister of Controlled Tri- } \\
\text { als (CENTRAL) in the } \\
\text { Cochrane Library }\end{array}$ & 2018 , Issue 1 & $\begin{array}{l}\# 1 \text { MeSH descriptor: [Exercise] explode all trees } \\
\# 2 \text { exercise* or physical activit* or training or (oxygen and (uptake or con- } \\
\text { sumption)) } \\
\# 3 \# 1 \text { or \#2 } \\
\# 4 \text { MeSH descriptor: [Liver Cirrhosis] explode all trees } \\
\# 5 \text { cirrho* } \\
\# 6 \text { \#4 or \#5 } \\
\# 7 \text { \#3 and \#6 }\end{array}$ \\
\hline
\end{tabular}

MEDLINE Ovid 1946 to February 2018

\section{1. exp Exercise/}

2. (exercise ${ }^{\star}$ or physical activit* or training or (oxygen and (uptake or consumption))).mp. [mp=title, abstract, original title, name of substance word, subject heading word, keyword heading word, protocol supplementary concept word, rare disease supplementary concept word, unique identifier]

\section{1 or 2}

4. exp Liver Cirrhosis/

5. cirrho*. $\mathrm{mp}$. [mp=title, abstract, original title, name of substance word, subject heading word, keyword heading word, protocol supplementary concept word, rare disease supplementary concept word, unique identifier]

\section{4 or 5}

\section{3 and 6}

8. $\left(\right.$ random $^{\star}$ or blind $^{*}$ or placebo* or meta-analys $\left.{ }^{\star}\right) \cdot \mathrm{mp}$. [mp=title, abstract, original title, name of substance word, subject heading word, keyword heading word, protocol supplementary concept word, rare disease supplementary concept word, unique identifier]

\section{7 and 8}

\section{Embase Ovid}

1974 to February 2018

\section{1. exp exercise/}

2. (exercise* or physical activit* or training or (oxygen and (uptake or consumption))).mp. [mp=title, abstract, subject headings, heading word, drug trade name, original title, device manufacturer, drug manufacturer, device trade name, keyword]

\section{1 or 2}


4. exp liver cirrhosis/

5. cirrho*.mp. [mp=title, abstract, subject headings, heading word, drug trade name, original title, device manufacturer, drug manufacturer, device trade name, keyword]

\section{4 or 5 \\ 7. 3 and 6}

8. $\left(\right.$ random $^{\star}$ or blind ${ }^{\star}$ or placebo* or meta-analys $\left.{ }^{\star}\right) \cdot \mathrm{mp}$. [mp=title, abstract, subject headings, heading word, drug trade name, original title, device manufacturer, drug manufacturer, device trade name, keyword]

9. 7 and 8

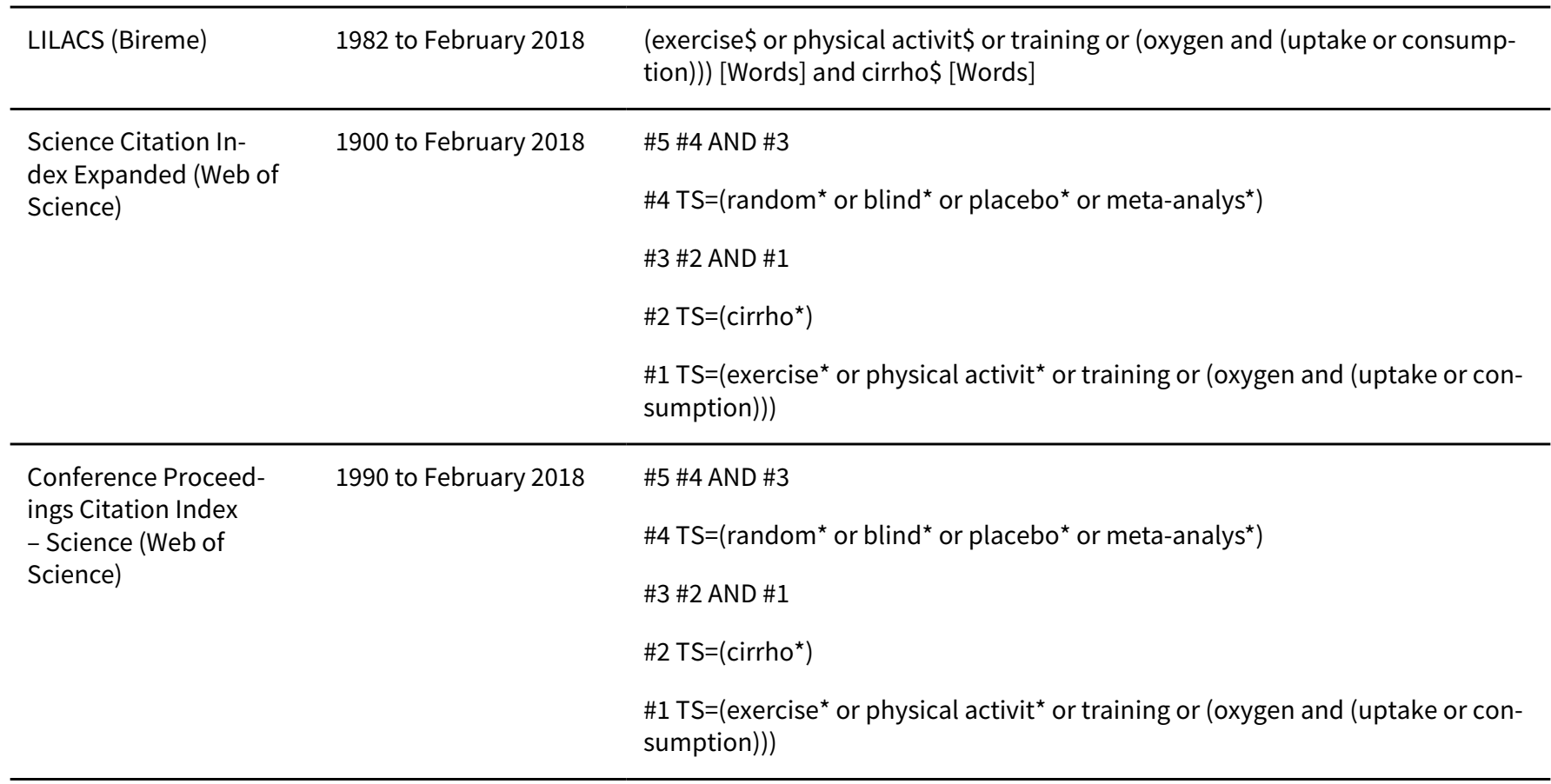

\section{CONTRIBUTIONS OFAUTHORS}

LA: selected trials for inclusion and extracted data; participated in the critical interpretation of statistical analyses; wrote the review draft. GD: selected trials for inclusion and extracted data; participated in the critical interpretation of statistical analyses; wrote the review draft. AR: selected trials for inclusion and extracted data; participated in the critical interpretation of statistical analyses; wrote the review draft. $\mathrm{HV}$ : validated the extracted data; wrote the review draft; participated in the critical interpretation of statistical analyses.

LLG: validated the extracted data; performed the statistical analyses; participated in the critical interpretation of statistical analyses; wrote the review draft.

All review authors approved the final version of the manuscript.

\section{DECLARATIONS OF INTEREST}

LA: none known

GD: none known

AR: none known

HV: none known

LLG: acted as investigator in studies funded by Abbvie, Merck, Intercept, and Norgine; received funding for travel expenses from Novo Nordisk; and participated in an educational meeting funded by Norgine and Eli Lilly. 


\section{SOURCESOF SUPPORT}

\section{Internal sources}

- No funding, Other.

\section{External sources}

- No funding, Other.

\section{DIFFERENCES BETWEEN PROTOCOLAND REVIEW}

We did not analyse secondary outcomes as strength measurements (hand grip strength, one-repetition maximum kicking strength), hepatic venous pressure gradient (HVPG), and functional tests (two-minute step test) because too few studies reported these data. Only one study reported strength measurements (Aamann 2018) and one measured HVPG (Macías-Rodríguez 2016).

We changed 'quality of life' into 'health-related quality of life'; preplanned secondary outcomes were grouped in the outcomes 'Anthropometric measurements' and 'Physical fitness'. We also searched Conference Proceedings Citation Index - Science.

\section{IN DEX TERMS}

\section{Medical Subject Headings (MeSH)}

*Exercise; *Resistance Training; Bicycling; Cause of Death; Liver Cirrhosis [complications] [mortality] [ ${ }^{\star}$ rehabilitation]; Oxygen Consumption; Physical Fitness; Quality of Life; Randomized Controlled Trials as Topic; Walk Test; Walking

\section{MeSH check words}

Female; Humans; Male 